\title{
A Study Examining Practice Style Traits of Physical Therapists: Do They Explain Practice Behaviors and Knowledge Translation?
}

Kristen M. Johnson

University of St. Augustine for Health Sciences

DOI: https://doi.org/10.46409/sr.UKFK5246

Follow this and additional works at: https://soar.usa.edu/dissertations

Part of the Adult and Continuing Education Commons, and the Physical Therapy Commons

\section{Recommended Citation}

Johnson, K. M. (2015). A Study Examining Practice Style Traits of Physical Therapists: Do They Explain Practice Behaviors and Knowledge Translation?. [Doctoral project, University of St Augustine for Health Sciences]. SOAR @ USA: Student Dissertations Collection. https://doi.org/10.46409/sr.UKFK5246

This Dissertation is brought to you for free and open access by the Student Research at SOAR @ USA. It has been accepted for inclusion in Student Dissertations by an authorized administrator of SOAR @ USA. For more information, please contact soar@usa.edu, erobinson@usa.edu. 
A Study Examining Practice Style Traits of Physical Therapists:

Do They Explain Practice Behaviors and Knowledge Translation?

\author{
by \\ Kristen M. Johnson \\ A dissertation submitted to the faculty of \\ University of St. Augustine for Health Sciences \\ In partial fulfillment of the requirements for the degree \\ Doctor of Education
}

March 31, 2015 
Copyright (C) 2015

by

Kristen M. Johnson 


\section{UNIVERSITY OF ST. AUGUSTINE FOR HEALTH SCIENCES}

The Undersigned Faculty Committee Approves the

Dissertation of

Kristen M. Johnson

A Study Examining Practice Style Traits of Physical Therapists:

Do They Explain Practice Behaviors and Knowledge Translation?

\begin{tabular}{c} 
Annie Burke-Doe, PT, MPT, PhD \\
Dissertation Chair \\
\hline Jane E. Sullivan, PT, DHS, MS \\
Committee Member \\
\\
Daniel R. Lofald, PhD \\
Department Chair \\
\\
\hline Cindy Mathena, PhD, OTR/L
\end{tabular}

Approval Date 


\section{DEDICATION}

This dissertation is dedicated to: my husband Britt for his endless encouragement, his ability to listen, listen, and listen some more, for his sacrifices of time and energy to allow me to follow my passion as a life-long learner, and for his faith in me to triumph in times of self-doubt; my children Kaylee, Rebecca, and Tyler for their curiosity of learning and for helping keep me grounded and focused during this journey; to my parents who provided me with a strong foundation in my faith and early education and who always inspired me to be passionate about my craft. 


\section{ACKNOWLEDGMENTS}

I would like to express my heartfelt gratitude to Dr. Annie Burke-Doe who has been an invaluable mentor since I started on this journey. She has a wonderful sense of creativity for teaching and clinical practice and has continually shared her resources to develop myself and those around her; clearly a knowledge broker. She gave me the opportunity to discuss research topics, and her reflection would create pictorial representations which would allow me to see the path more clearly along the way. Her novel and creative spirit taught me the importance of this journey in continuing along the road as a life-long learner and that this was not simply a destination. I have been forever shaped by her mentorship to translate the art of teaching and clinical practice to promote the highest level of motivation from both students and patients; for this I am eternally grateful. Most importantly, I am thankful that she allowed me to develop educational research in my area of passion-outcome measurement, while maintaining the academic rigor for the requirements of a dissertation.

Special thanks are given to Dr. Jane Sullivan for her virtual and on-going support through this dissertation process. She and her team developed a thoughtful and evidence-based course specific to the knowledge translation of outcome measures, and it was this work that helped shape my dissertation. Her research, teaching, and dedication to the profession is exemplary, and I am honored to have received her expertise with this research project. If I can incorporate just a portion of her skills into my teaching and clinical practice, I am surely bound for success.

Appreciation is expressed to Dr. Dan Lofald for his support and continual influence of creating quality educational research. Dan has a contagious spirit for the art 
of teaching and learning and because of this I continue to elevate my teaching practices and share this same excitement with my own students. His counsel caused me to self-reflect at a whole new level, and I am truly thankful that he opened my eyes in understanding the eminent need of combining a strong educational background within the health sciences.

Sincere appreciation goes to Dr. Cindy Mathena for her efforts in program development and her leadership in validating and directing me to colleagues who share my passions. She supported me through the terminal degree process and would always greet me with a calming smile, asking me about my family and keeping me grounded within my professional and personal life.

Words cannot express my sincere appreciation to my family for allowing me to pursue the highest education. Their sacrifices, love, prayers, and continual encouragement made something I never thought I could accomplish a reality. Finally, I would like to acknowledge my strong supportive network of friends and colleagues. Despite not being able to acknowledge each of you individually, many of you encouraged, listened, and participated in this process. To each of you goes a part of this success and a tremendous amount of gratitude. 
DEDICATION $\ldots \ldots \ldots \ldots \ldots \ldots \ldots \ldots \ldots \ldots \ldots \ldots \ldots \ldots \ldots \ldots \ldots$, iv

ACKNOWLEDGMENTS. . . . . . . . . . . . $\ldots \ldots \ldots \ldots \ldots \ldots$

LIST OF TABLES. ........................

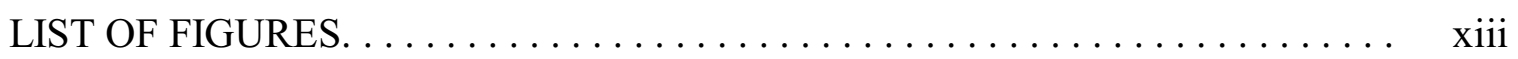

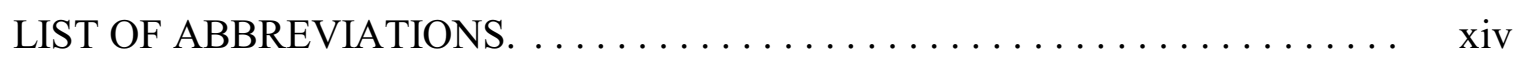

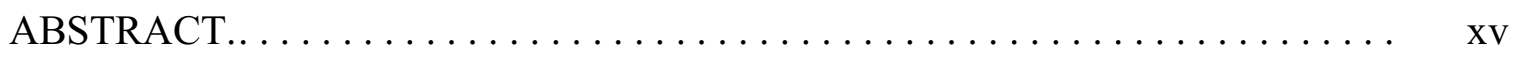

CHAPTER 1 -INTRODUCTION AND THEORETICAL FRAMEWORK. . . . . . 1

Background. . . . . . . . . . . . . . . 1

Evidence-Based Practice in Physical Therapy................ 2

Guidelines for Evidence-Based Practice in Physical Therapy:

Conceptual Frameworks and Clinical Decision-Making............. 3

Knowledge Translation and Theoretical Frameworks............ 5

CHAPTER 2-PROBLEM STATEMENT AND RESEARCH QUESTIONS. . . . 12

Problem Statement. . . . . . . . . . . . . . . . . . . . 12

Purpose of Study. . . . . . . . . . . . . . 12

Significance. .............................. 13

Research Questions. ......................... 14

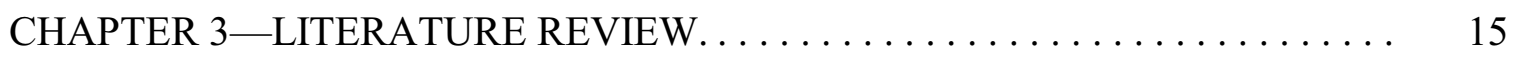

Evidence-Based Medicine and Evidence-Based Practice. . . . . . . . . . 15

Evidence-Based Practice in Physical Therapy. . . . . . . . . . . . 18

Guidelines for Evidence-Based Practice in Physical Therapy:

Decision-Making and Conceptual Frameworks................. 21 
Definition and Application of Standardized Outcome Measures. . . . . . . . 26

Hypotheses............................... 51

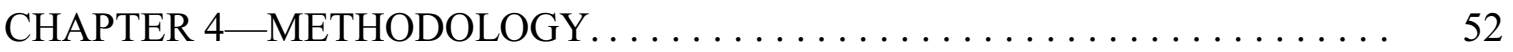

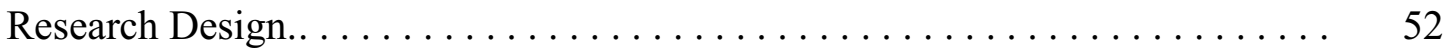

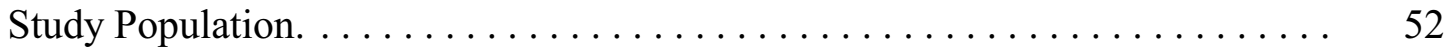

Data Collection Tools. ............................... 52

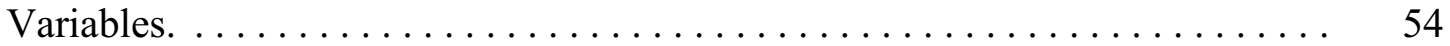

Dependent Variables. ........................ 54

Independent Variables. . . . . . . . . . . . . . . . . . . 54

Statistical Analysis.............................. 54

CHAPTER 5-DATA ANALYSIS AND PRESENTATION OF RESULTS. . . . . 56

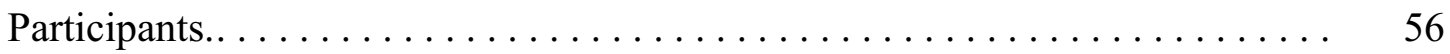

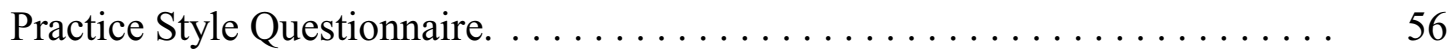

Evidence-Based Practice Questionnaire Domains and Their Relevance to Evidence-Based Practice and Guidelines/Outcome Measures.. . . . . . . . . . . .

Evidence-Based Practice Questionnaire-Individual Questions

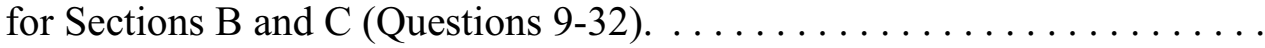

Section B: Questions about attitudes toward, use of, and perceived benefits and limitations of evidence-based practice.

Section C: Questions about attitudes toward and use of clinical practice guidelines/outcome measures. . . . . . . . . .

Combination of Both the Practice Style and Evidence-Based Practice Questionnaires. . . . . . . . . . . . . . . . . . . . . . . . . . . . . 68

Post Hoc Analysis. . . . . . . . . . . . . . . . . . . . . . . . . . . . . . 69

Tukey HSD. . . . . . . . . . . . . . . . . . . . . . . . 69 
Chi Square Analyses: Evidence-based Practice Questionnaire by

Practice Style Trait. . . . . . . . . . . . . . . . . . . . . . . . 69

Chi Square Analyses: Demographics.................... 72

CHAPTER 6-DISCUSSION, IMPLICATIONS OF RESEARCH,

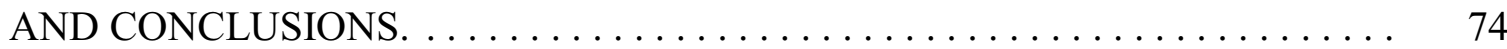

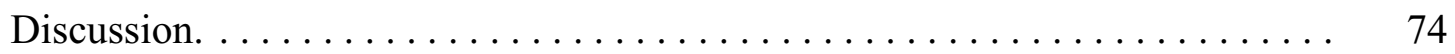

Practice Style Traits. . . . . . . . . . . . . . . . . . 74

Evidence-Based Practice Questionnaire. ................. 76

Combination of Practice Style Traits and Evidence-Based

Practice Questionnaire. . . . . . . . . . . . . . . . . . . . 80

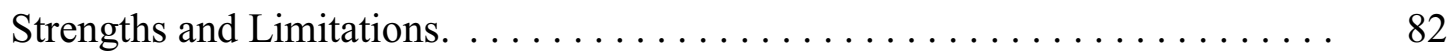

Implications of Research. . . . . . . . . . . . 84

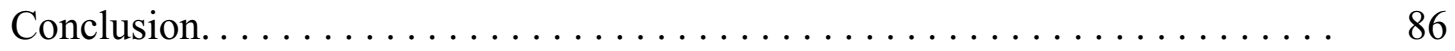

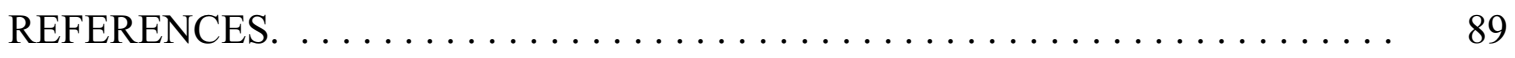

APPENDICES

A. Practice Style Questionnaire. . . . . . . . . . . . . . . . . . 101

B. Evidence-Based Practice Questionnaire. ................. 103 


\section{LIST OF TABLES}

PAGE

Table 1. The Five-Step Evidence-Based Practice Process. . . . . . . . . . . . . . 17

Table 2. Summary of Practice Style Traits. . . . . . . . . . . . . 46

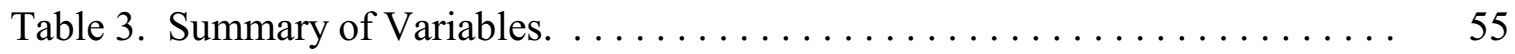

Table 4. Demographic Information for 79 Participants. . . . . . . . . . . 57

Table 5. Practice Style Questionnaire-Scale Scores to Determine

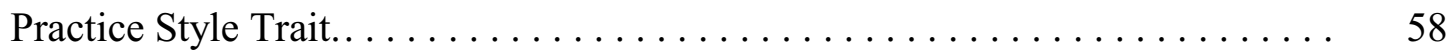

Table 6. Practice Style Questionnaire-Total Scores to Determine

Practice Style Trait.. . . . . . . . . . . . . . . . . . . .

Table 7. Question 9 (Attitude Domain) - I Consider It Necessary to Apply EBP in the Daily Practice of Physical Therapy............... 60

Table 8. Question 10 (Attitude Domain) - I Think it Creates Unreasonable

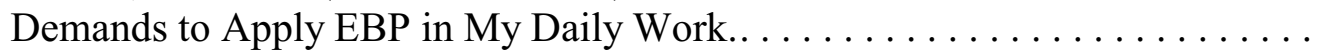

Table 9. Question 11 (Attitude Domain)—I Want to Learn and Improve the Knowledge and Skills Necessary to Apply EBP in My Work. . . . . . . . . . .

Table 10. Question 12 (Attitude Domain)—Strong Evidence Is Lacking for Most Treatments That I Use for My Patients. . . . . . . . . . . . . . . . . . .

Table 11. Question 13 (Attitude Domain)_EBP Can Help Me Make Decisions in the Choice of Treatment. . . . . . . . . . . . . . .

Table 12. Question 14 (Behavior Domain)—Number of Scientific Articles Related to My Clinical Work That I Read During a Typical Month. . . . . . . . . .

Table 13. Question 15 (Behavior Domain)—Number of Times I Use PubMed or Other Databases to Search Literature That Is Relevant to My Clinical Work During a Typical Month. . . . . . . . . . . . . . . .

Table 14. Question 16 (Knowledge Domain) - I Know How to Access Relevant Databases. ............................

Table 15. Question 17 (Barriers and Prerequisites) — At My Place of Work the Use of Current Research Is Encouraged.. . . . . . . . . . . . . . . 
Table 16. Question 18 (Attitude Domain) — I Feel Confident in My Ability to Find Relevant Research to Answer My Clinical Questions.. . . . . . . . . . . .

Table 17. Question 19 (Attitude Domain) - I Feel Confident in My Ability to Treat My Patients According to Current Evidence. . . . . . . . . . . . .

Table 18. Question 20 (Attitude Domain)—I Consider It Important That Easily Available Evidence-based Guidelines/Outcome Measures Related to My Work Exist. . . . . . . . . . . . . . . . . . . . . .

Table 19. Question 21 (Attitude Domain) - I Consider It Important to Use Evidence-based Guidelines/Outcome Measures in My Work. . . . . . . . . . . .

Table 20. Question 22 (Knowledge Domain) —I'm Aware That Evidencebased Guidelines/Outcome Measures for Diagnoses Relevant to My

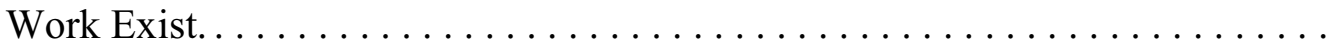

Table 21. Question 23 (Knowledge Domain) - I Know How and Where to Find Evidence-based Guidelines/Outcome Measures Related to My Work on the Internet. . . . . . . . . . . . . . . . . . . .

Table 22. Question 24 (Barriers and Prerequisites) —I Have Fast and Easy Access to Relevant Evidence-based Guidelines/Outcome Measures at

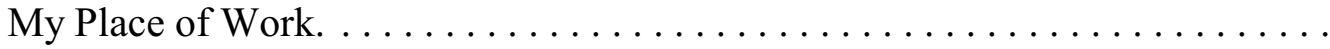

Table 23. Question 25 (Behavior Domain)—I Use Evidence-based Guidelines/Outcome Measures in My Work. . . . . . . . . . . . . . . .

Table 24. Question 26 (Knowledge Domain) - I Can Integrate the Patients' Preferences With Evidence-based Guidelines/Outcome Measures.

Table 25. Question 27 (Attitude Domain)_Evidence-based Guidelines/ Outcome Measures Are Important to Facilitate My Work.

Table 26. Question 28 (Attitude Domain)—Evidence-based Guidelines/ Outcome Measures Are Important so That the Patients Receive the Best Possible Treatment.. . . . . . . . . . . . . . . . . . . . . . . .

Table 27. Question 29 (Attitude Domain)_Evidence-based Guidelines/ Outcome Measures Are Important so That the Patients Receive Equal

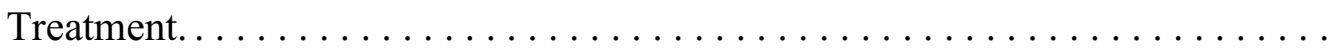


Table 28. Question 30 (Barriers and Prerequisites)—Factors below That Constitute the Greatest Barriers to Using Evidence-based Guidelines/ Outcome Measures.. . . . . . . . . . . . . . . . . . . . . . . . . . . . . . . . .

Table 29. ANOVA-Practice Style Trait With Four Domains of Evidencebased Practice Questionnaire........................ 68

Table 30. Test for Homogeneity of Variance. . . . . . . . . . . . . . . . . 69

Table 31. Question 15 (Behavior Domain)—Number of Times I Use PubMed or Other Databases to Search Literature That Is Relevant to My Clinical Work During a Typical Month. .................

Table 32. Question 16 (Knowledge Domain) - I Know How to Access Relevant Databases. ............................. 70

Table 33. Question 17 (Barriers and Prerequisite Domain) - At My Place of Work the Use of Current Research is Encouraged. . . . . . . . . . . 70

Table 34. Question 19 (Attitude Domain) —I Feel Confident in My Ability to Treat Patients According to Current Evidence.

Table 35. Question 21 (Attitude Domain) - I Consider It Important to Use Evidence-Based Guidelines/Outcome Measures in My Work.. . . . . . . . . . . .

Table 36. Question 25 (Behavior Domain) -I Use Evidence-Based Guidelines/Outcome Measures in My Work. .

Table 37. Question 26 (Knowledge Domain) - I Can Integrate the Patients' Preferences With Evidence-Based Guidelines/Outcome Measures.. . . . . . . . . . .

Table 38. Question 27 (Attitude Domain)—Evidence-Based Guidelines/ Outcome Measures Are Important to Facilitate My Work.

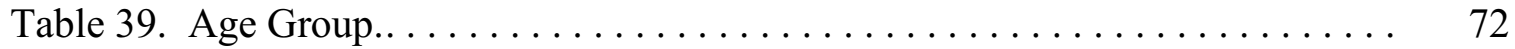

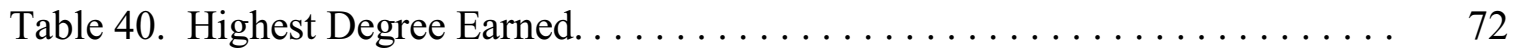

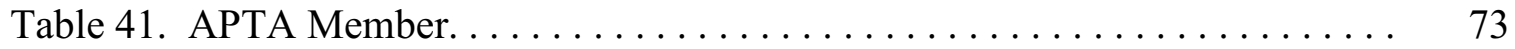

Table 42. Primary Place of Employment. . . . . . . . . . . . . . . 74

Table 43. Portion of Total Time Spent in Patient Care.. . . . . . . . . . . . . . . . . . 74 


\section{LIST OF FIGURES}

PAGE

Figure 1. Knowledge to action (KTA) cycle................. 6

Figure 2. Evidence-based practice. $\ldots \ldots \ldots \ldots \ldots \ldots \ldots \ldots \ldots \ldots \ldots \ldots$

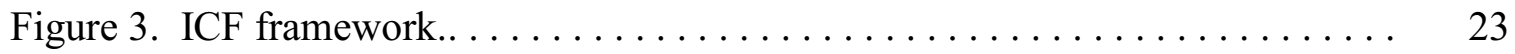

Figure 4. Elements of the patient/client management system........... 26

Figure 5. Knowledge to Action (KTA) cycle with supporting

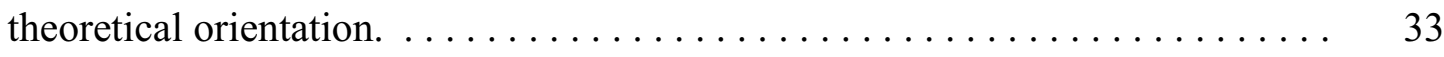

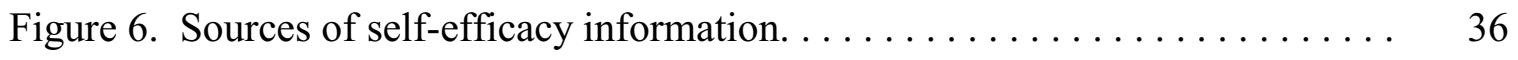

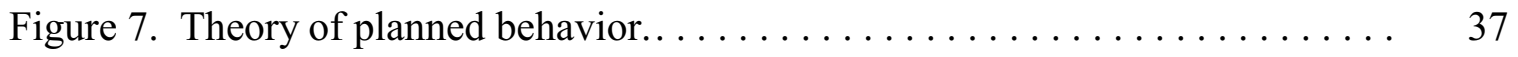

Figure 8 . Transtheoretical model (stages of change) $\ldots \ldots \ldots \ldots \ldots \ldots \ldots \ldots$

Figure 9. Pictorial representation of practice style traits............. 46 


\section{LIST OF ABBREVIATIONS}

APTA: American Physical Therapy Association

BBS: Berg Balance Scale

CAPTE: Commission on Accreditation in Physical Therapy Education

CIHR: Canadian Institutes of Health Research

DHI: Dizziness Handicap Inventory

EBCPGs: Evidence-based Clinical Practice Guidelines

EBM: Evidence-based Medicine

EBP: Evidence-based Practice

FMA: Fugl-Meyer Assessment

HOAC II: Hypothesis-Oriented Algorithm for Clinicians II

ICF: International Classification of Functioning, Disability, and Health

KT: Knowledge Translation

KTA: Knowledge to Action

MCID: Minimally Clinically Important Difference

MDC: Minimal Detectable Change

OM: Outcome Measure

SIS: Stroke Impact Scale

STREAM: Stroke Rehabilitation Assessment of Movement

WCPT: World Confederation for Physical Therapy

WHO: World Health Organization 


\begin{abstract}
Background: The advancement of evidence-based practice (EBP) has generated a flurry of outcome measures (OMs) and continuing education courses to assist in the creation and tailoring of this knowledge to the clinical environment. Despite the development of these resources, little is known about the attributes and behaviors of the physical therapist for knowledge translation (KT) into clinical practice.

Purpose: To determine the practice style traits of physical therapists who attended an evidence-based continuing education course on Oms and to determine their perceived barriers, facilitators, attitudes, knowledge, behaviors, and prerequisites for KT.

Methods: Seventy-nine physical therapists completed two standardized, validated surveys titled the Practice Style Questionnaire and the EBP Questionnaire. These questionnaires elicited information on practice style traits and the cognitive and motivational variables related to their behavior for KT of OMs in clinical practice.

Results: Twenty-eight percent were seekers, $49 \%$ were pragmatists, and $23 \%$ were receptives. All practice style traits reported high levels of knowledge $(>81 \%)$ in their abilities to search the evidence related to OMs and many $(>88 \%)$ considered it important to use OMs in their work. Despite these responses, $31 \%$ of the participants did not use OMs in their daily clinical practice.

Conclusions: Differences in practice style traits show that physical therapists differ in their behaviors toward new information and how evidence is applied clinically. Future KT research is warranted to understand the impact of matching educational interventions to traits and to determine the best practices for furthering KT of OMs in clinical practice.
\end{abstract}




\section{Chapter 1}

Introduction and Theoretical Framework

\section{Background}

In healthcare today, there is a vast amount of information to guide clinical decision-making. There has been a significant shift among practicing clinicians from a more traditional approach of solely using the opinions of authority leaders to embracing current research evidence to guide clinical practice (D. U. Jette et al., 2003). In 2015, practicing clinicians are expected to translate their clinical experience along with the use of current research evidence to make optimal decisions that impact the delivery of patient care (Menon, Korner-Bitensky, Kastner, McKibbon, \& Straus, 2009). Healthcare has moved from concepts of what were once defined as evidence-based medicine (EBM) into what is presently called evidence-based practice (EBP). In years past, the most widely used definition of EBP comes from Sackett (1997):

EBP is the conscientious, explicit and judicious use of current best evidence in making decisions about the care of the individual patient. It means integrating individual clinical expertise with the best available external clinical evidence from systematic research. (p. 71)

In 2002, Sackett elaborated on the earlier definition to include the integration of clinical expertise and the patient values. There should be significant emphasis placed on a practicing clinician's expertise, including their education, cumulative clinical experience, and clinical skills (Sackett \& Haynes, 2002). Evidence-based practice also prioritizes the patient experience, as patients each have their own unique goals, 
preferences, and expectations. Lastly, Sackett and Haynes (2002) defines the best research evidence as research that has been conducted using sound methodology.

\section{Evidence-Based Practice in Physical Therapy}

Evidence-based practice, as the integration of all three components-clinical expertise, the best research evidence and patient values and preferences - is critical for

optimal delivery of healthcare (Sackett \& Haynes, 2002). Physical therapy as a healthcare profession also supports EBP. Vision 2020 (American Physical Therapy Association [APTA], 2013), which was adopted by the American Physical Therapy Association's House of Delegates in 2000, provides a vision sentence for physical therapy: By 2020, physical therapy will be provided by physical therapists who are doctors of physical therapy, recognized by consumers and other health care professionals as the practitioners of choice to whom consumers have direct access for the diagnosis of, interventions for, and prevention of impairments, activity limitations, participation restrictions, and environmental barriers related to movement, function, and health. (APTA, 2013, para. 2)

In order to achieve this vision, EBP must be at the forefront of our professional behaviors. In 2011, the APTA's House of Delegates prompted further steps to proposing Beyond Vision 2020, which furthers the earlier statement by highlighting the importance of movement, quality of life, and how the profession serves society. This proposed Beyond Vision 2020 (APTA, 2015b) embraces Sackett and Haynes' (2002) definition of EBP and suggests to other healthcare professions and consumers that physical therapists are evidence-based practitioners. 


\section{Guidelines for Evidence-Based Practice in Physical Therapy: \\ Conceptual Frameworks and Clinical Decision-Making}

In physical therapy, a variety of conceptual frameworks are used to guide EBP and clinical decision-making. One example of a commonly used conceptual framework is the Hypothesis-Oriented Algorithm for Clinicians II (HOAC II; O’Sullivan, Schmitz, \& Fulk, 2014). The HOAC II represents the clinical decision-making processes that can be employed during each aspect of the patient management process (Rothstein, Echternach, \& Riddle, 2003). The Guide to Physical Therapist Practice (APTA, 2014) is another example of a conceptual framework used to guide EBP and clinical decision-making in physical therapy. In the Guide to Physical Therapist Practice, the patient management process includes: examination of the patient, evaluation of data gathered, determination of a physical therapy diagnosis and prognosis to include the plan of care, implementation of intervention, and assessment of patient outcomes.

In addition to the HOAC II and the Guide to Physical Therapist Practice, the APTA adopted the World Health Organization's (WHO's) International Classification of Functioning, Disability, and Health (ICF) model in 2008 (ICF, 2001). The ICF model is another conceptual framework that employs explicit use of terminology to identify health conditions and subsequent patient problems. It then further categorizes this information into three domains: body functions and structure, activity, and participation. These three domains are then considered along with a patient's contextual factors including environmental and personal factors in a multidimensional framework for clinical decision-making (ICF, 2001). 
During the patient management process, a physical therapist may use the HOAC II, Guide to Physical Therapist Practice, and the ICF model as conceptual basis for EBP and clinical decision-making. Optimal outcomes and ultimately a patients' quality of life depends on the use of EBP during each of the components of the patient management process (Bernhardsson \& Larsson, 2013). Outcomes, as the final step in the patient management process, are defined by the Guide to Physical Therapist Practice as the result of physical therapy interventions across multiple domains to include, but are not limited to changes in impairments, activity, and participation limitations, as they relate to the pathology, patient satisfaction, societal resources, and prevention of future conditions (APTA, 2014). Assessment of this final step in the patient management process involves specific tests and measures during the examination and evaluation stages (APTA, 2014).

During the patient examination, tests and measures are used to gather objective data about body structure/function impairments, activity limitations, and participation restrictions. Data obtained from the use of tests and measures are then considered during the evaluation stage of the process to help the PT to formulate a PT diagnosis, develop a prognosis, goals, and a plan of care. The same tests and measures are used subsequently throughout the episode of care to determine if progress has been made. In addition, standardized outcome measures (OMs), which are specific tests and measures, should also be used in this final step of the patient management process. Outcome measures, also when used from before and after an intervention, defined by D. U. Jette, Halbert, Iverson, Miceli, and Shah (2009) "are standardized in that they use close-ended questionnaire formats or specific protocols for implementation, provide scores that allow quantitative assessment of ability, and have been evaluated for their psychometric 
properties" (p. 126). Outcome measures are used to assist in the diagnosis and prognosis of patient care in addition to tracking changes in human performance and health status (Potter, Fulk, Salem, \& Sullivan, 2011; Sullivan, Andrews, Lanzino, Peron, \& Potter, 2011). Outcome measures, unlike tests and measures, such as posture and manual muscle testing, have research evidence that provides psychometric properties for specific patient populations. The use of OMs have been shown to contribute to EBP and improve both patient outcomes and optimize quality of life (Fritz, Cleland, \& Brennan, 2007; Liddle, David Baxter, \& Gracey, 2009; Overmeer, Linton, Holmquist, Eriksson, \& Engfeldt, 2005; Rutten et al., 2010). Understanding and applying the psychometric properties assists in patient-specific clinical decision-making and the translation of knowledge into EBP.

\section{Knowledge Translation and Theoretical Frameworks}

Despite the significant growth of EBP across health professions and the numerous conceptual frameworks that use EBP to guide clinical decision-making in physical therapy, there is an important consideration with the application of knowledge, often referred to as knowledge translation (Straus, Tetroe, \& Graham, 2013). Knowledge translation (KT) has been defined by the Canadian Institutes of Health Research (CIHR, 2014) as "a dynamic and iterative process that includes the synthesis, dissemination, exchange and ethically sound application of knowledge to improve health, provide more effective health services and products and strengthen the healthcare system" (para 1). This definition has been accepted by the United States National Center for Dissemination of Disability Research and the World Health Organization (Straus et al., 2013). 
Because KT has many definitions and frameworks with underlying theories, it is often confused by health care practitioners and researchers alike (Estabrooks, Thompson, Lovely, \& Hofmeyer, 2006; MacDermid \& Graham, 2009; Rycroft-Malone \& Bucknall, 2013; Tabak, Khoong, Chambers, \& Brownson, 2012; Wensing et al., 2005). A widely used KT conceptual framework has been developed by Graham and colleagues and is referred to as the Knowledge to Action (KTA) cycle (Graham et al., 2006). The KTA cycle is depicted in Figure 1.

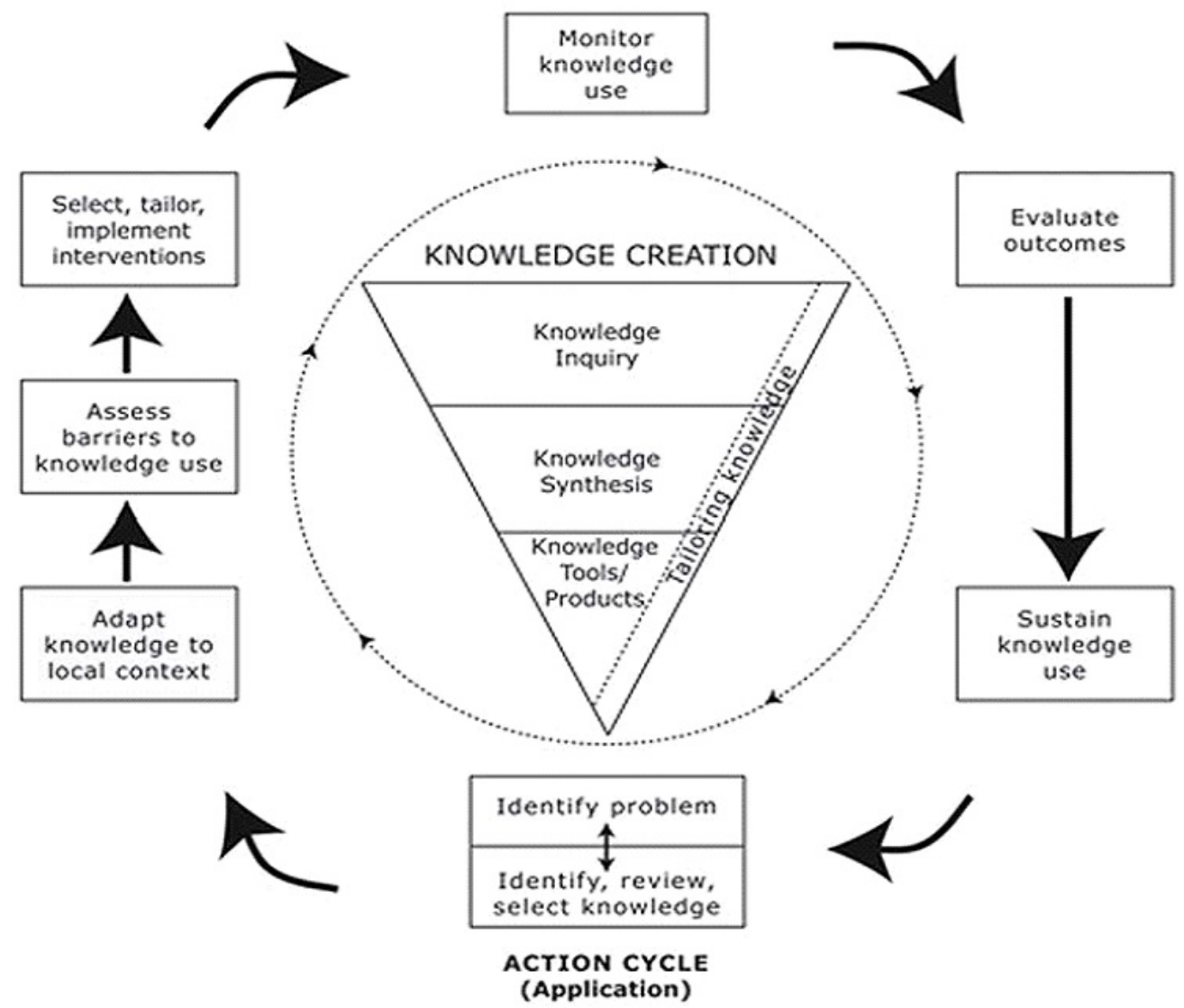

Figure 1. Knowledge to action (KTA) cycle. Adapted from What Is Evidence-Based Practice (EBP)? by the Duke University Medical Center, 2015, retrieved from http://guides.mclibrary.duke.edu/c.php?g=158201\&p=1036021 
The KTA cycle was developed after reviewing over 30 theories specific to planned action theories (Graham et al., 2006). The KTA cycle has been accepted as the model for promoting research and the framework for the processes of KT by the CIHR (Straus et al., 2013). Figure 1 displays the dynamic and complex processes between knowledge creation and application of this knowledge within the action cycle (Graham et al., 2006). Once knowledge is created, synthesized and tailored to the learner, it can enter the KTA cycle. The action cycle involves seven action phases that include: (a) identifying the problem, (b) adaption of knowledge to local context, (c) assessing barriers and facilitators to knowledge use, (d) selecting, tailoring, implementing interventions, (e) monitoring knowledge use, (f) evaluating outcomes, and (g) sustaining knowledge use (Graham et al., 2006). In clinical practice, each action phase can provide information about the next phase in sequential order. For example, assessing barriers and facilitators to knowledge use (action phase 3) can impact the next phase by providing an intervention to enhance KT (action phase 4) after the barriers and facilitators are determined (Straus et al., 2013). Additionally, because knowledge creation and synthesis is so vital and located in the center of the KTA cycle, it can simultaneously influence action phases at any point in time (Straus et al., 2013)

Published papers in the field of KT relate mainly to the health professions of physicians and nurses, and there is limited research on KT and the KTA cycle in physical therapy (Straus et al., 2013). Dr. Gail Jensen, a physical therapist, in her 2011 APTA Mary McMillan Lecture titled Learning: What Matters Most is quoted as stating, "Learning is defined as the knowledge acquired by the systemic study in any field of scholarly application, the act or process of acquiring knowledge or skill, and the 
modification of behavior through practice, training, or experience" (p. 1677). Dr. Jensen is describing the importance of KT and the necessary changes in behavior in order for the advancement and translation of EBP. In physical therapy, the research evidence is rich with examples about acquiring new knowledge (Maher, Moseley, Sherrington, Elkins, \& Herbert, 2008); however, there is a lack of research about how this knowledge, once gained, is applied in the clinical setting (Bernhardsson \& Larsson, 2013).

There are numerous accounts of the struggles with KT for physical therapists. For example, these struggles include time constraints, lack of access to needed equipment and resources, and the knowledge itself for application of EBP (Dumoulin, Korner-Bitensky, \& Tannenbaum, 2007; D. U. Jette et al., 2003; D. U. Jette et al., 2009; Korner-Bitensky, Desrosiers, \& Rochette, 2008; Menon-Nair, Korner-Bitensky, \& Ogourtsova, 2007; Rochette, Korner-Bitensky, \& Desrosiers, 2007). Despite these struggles, it is well documented that if a physical therapist demonstrates adherence to clinical practice guidelines, including the use of recommended OMs as forms of evidence, improved patient outcomes and quality of care results (Duncan et al., 2002; Fritz et al., 2007; Liddle et al., 2009; Overmeer et al., 2005; Rutten et al., 2010). In addition to the limited research on application of knowledge or KT, there is little research evidence about how the physical therapists' behaviors and attitudes are modified during KT and EBP (Bernhardsson \& Larsson, 2013). There is a critical need to understand more about the scholarly application and behavioral modifications of KT and its connections to the KTA cycle in physical therapy.

This dissertation is interested in understanding more about three specific action phases in the KTA cycle within physical therapy. Unique to the use of OMs in clinical 
practice, there is no evidence to date in terms of how knowledge is adapted to the local context (action phase 2 in KTA cycle). The local context refers to a physical therapists' practice setting or daily clinical environment in which they are applying EBP to optimize patients' outcomes and quality of life (Bernhardsson \& Larsson, 2013). Understanding more about how OMs are used within the clinical setting helps to align the research evidence to the local context or daily practice setting (Straus et al., 2013). One way to better understand how knowledge is adapted to the local, clinical context is to determine the attributes of practicing physical therapists. Green, Gorenflo, and Wyszewianski (2002) have described and validated the clinical attributes of physicians and refer to these attributes as practice style traits. Practice style traits are based on a theoretical framework describing how a practicing clinician responds to new information. A clinician can be classified as a seeker, a receptive, a traditionalist, or a pragmatist. These roles are based on three underlying theoretical constructs that include: (a) how a practicing clinician weighs research evidence versus experience, (b) their degree of comfort while engaged in clinical practice, and (c) how evidence impacts their workload (Green et al., 2002). There is a need to understand how the theoretical constructs of these practice style traits, as supported by cognitive and educational theories, influence this second phase in the KTA cycle (Straus et al., 2013). This research will provide the profession of physical therapy with knowledge about how a practicing physical therapist is classified according to their practice style trait (Green et al., 2002) and more importantly how their trait impacts KT and the later stages in the KTA cycle (Straus et al., 2013).

In addition, this dissertation is interested in the third and fifth phases in the KTA cycle, which are assessing barriers and monitoring knowledge use. Straus and colleagues 
(2013) believe there is no "magic bullet" for KT research; however, understanding the barriers and facilitators to knowledge use (action phase 3 in KTA cycle) is the most important phase for the potential users of this knowledge. When the terms "barriers and facilitators to knowledge use" are used as keywords during a literature search often they are in relation to "the context of beliefs about capabilities," of which they are key components (Straus et al., 2013, p. 122). Straus and colleagues (2013) report the third action phase of KT relates to beliefs about capabilities, including "the concept of perceived behavior control, a determinant of behavior proposed by the cognitive psychology theory of planned behavior" (p. 122). The cognitive psychology theories support that identification of factors that influence a physical therapists' behaviors are based on their perceived "belief about capabilities" (Ajzen, 2005). A Cochrane Review concluded beliefs about capabilities had the most influence on a practicing clinician's behavior and intention for knowledge use; therefore, identifying both barriers and facilitators, to the use of OMs, would be a strong variable in understanding a physical therapist's behavior and intention (Baker et al., 2010).

Lastly, this dissertation is interested in applying the fifth action phase in the KTA cycle, monitoring knowledge use, to the use of OMs. Although the creation and tailoring of knowledge is necessary, as viewed in the center of the KTA cycle, greater interest should be directed at studying the impact of this knowledge on patient care and monitoring the physical therapists' knowledge use (Straus et al., 2013). In the KTA cycle, this fifth action phase occurs after the physical therapist has received new knowledge, for example in the form of an educational intervention. Monitoring knowledge use is critical to determine the "uptake" and application of new knowledge; 
however, research in this action phase is in its infancy (Straus et al., 2013). Although supported by both cognitive psychology and educational theories, this action phase is a challenging one to study and measure. Knowledge use considers three classifications or models including conceptual, instrumental, and persuasive forms of knowledge use (Straus et al., 2013). Conceptual knowledge use refers to changes in knowledge, understanding, or attitudes; instrumental knowledge use describes changes in practice behavior as a result of knowledge use. Lastly, persuasive knowledge use is used to attain a higher position or rank or to gain a larger profit as it relates to patient care. Monitoring knowledge use, considering these conceptual models, has not been studied in physical therapy, as it relates to the application of OMs in clinical practice. Based on the theories and models that support this fifth action phase, understanding more about a practicing therapists' attitudes, changes in knowledge, behavior, and prerequisites for knowledge will assist with filling the $\mathrm{KT}$ gap as it relates to the use of OMs in clinical practice. 
Chapter 2

Problem Statement and Research Questions

\section{Problem Statement}

Within health professions, there continues to be a gap between current research evidence and translation of this research evidence into clinical practice. There is an expectation that health professionals remain current with the evidence, despite the increase in volume (D. U. Jette et al., 2003). In physical therapy, the advancement of evidence-based practice (EBP) has generated a flurry of clinical practice guidelines and continuing education courses to assist in the creation of knowledge and the tailoring of knowledge as central components in the Knowledge to Action (KTA) cycle (Bernhardsson \& Larsson, 2013; Straus et al., 2013). Despite the development of these potential resources, little is known about how this new knowledge is applied to specific action phases within the KTA cycle.

Little research has been done to understand knowledge translation (KT) within physical therapy. Specific to this dissertation, components of the KTA cycle and its supporting theories will be applied with regards to KT and the use of outcome measures (OMs) in clinical practice. This dissertation is interested in three components of the KTA cycle: (a) adaption to the local context (action phase 2), (b) assessing barriers and facilitators to knowledge use (action phase 3), and (c) monitoring knowledge use (action phase 5).

\section{Purpose of Study}

The purpose of this study is to determine the practice style traits of physical therapists who attended an evidence-based continuing education course on OMs and to 
determine their perceived barriers, facilitators, attitudes, knowledge, behaviors, and prerequisites for KT as action phases within the KTA cycle.

\section{Significance}

From these data, it is expected that the researcher will determine if gaining new knowledge in the area of Oms, by attending a specific continuing education course, was translated into the KTA cycle. First, determining the physical therapist's practice style traits will assist in understanding how physical therapists apply new knowledge in their clinical setting. Relating participant demographics and practice style traits can assist in the future development of educational strategies for continuing education courses, because curriculum and course development should be tailored to match the practice traits of the physical therapist in order for the advancement of KT (Hadouda et al., 2009). Determining a physical therapist's practice style trait in terms of how their knowledge is adapted to their local or clinical environment (action phase 2), such as how they weigh evidence versus experience, can predict how they apply new information. Determining the physical therapist's trait allows us to predict how their trait relates to this and additional action phases of assessment of barriers (action phase 3) and monitoring knowledge use (action phase 5) within the KTA cycle. For example, knowing a physical therapist's practice style trait may yield differences in what they view as barriers or facilitators to KT. When assessment of practice style trait (action phase 2) is combined with barriers and facilitations (action phase 3), it may then further impact the later action phases in the KTA cycle, because their attitudes and behaviors may/may not be open to the use of OMs in clinical practice. 
It is expected that the researcher will understand more about the third and fifth action phases within the KTA cycle. This will be determined by understanding the barriers, facilitators, attitudes, knowledge, behaviors, and prerequisites to knowledge use within the KTA cycle as it relates to the use of OMs in clinical practice. Understanding more about action phases in the KTA cycle, across a variety of clinical settings, can assist in uncovering reasons as to why OMs are used applied in clinical practice. Knowing more about the attitudes and behaviors of physical therapists who use EBP, in the form of OMs, will ultimately assist in determining ways of increasing the use of OM in clinical practice. From the research, it has been determined that when using EBP, in form of OMs, patient care can be optimized, and there is a greater potential for improving the patient's outcomes and quality of life (Hadouda et al., 2009). Efficiency of patient care delivery is dependent on the use of the best available evidence, and determining the factors that influence KT within the KTA cycle are critical (American Physical Therapy Association [APTA], Neurology Section, 2015b).

\section{Research Questions}

1. Does understanding how knowledge was adapted to the local context (i.e., the practice style traits of practicing physical therapists) predict KT?

2. Within the KTA cycle, what are the barriers and prerequisites to knowledge use of OMs in clinical practice?

3. Within the KTA cycle, do characteristics of monitoring knowledge use of OMs, including attitudes, knowledge, and behaviors, determine the success of KT in clinical practice? 
Chapter 3

Literature Review

\section{Evidence-Based Medicine and Evidence-Based Practice}

The birth of evidence-based medicine (EBM) dates back to 1972 when Archie Cochrane published a seminal book titled Effectiveness and Efficiency: Random Reflections on Health Services. Over the past $40+$ years, research has continued to evolve (Cochrane, 1989). Cochrane (1989) promoted the importance of using current research evidence during the clinical decision-making process and further prompted a large challenge to the healthcare community of organizing critical summaries of randomized controlled trials for each medical specialty. Evidence-based medicine was formally defined by Sackett, Rosenberg, Gray, Haynes, and Richardson (1996) as "the conscientious, explicit and judicious use of current best evidence in making decisions about the care of individual patients" (p. 71). The term EBM was later transitioned into the broader term of evidence-based practice (EBP; Sackett \& Haynes, 2002) and included integrating individual clinical expertise of not only the individual's experience, but also their education and clinical skills. In addition, he stressed the importance that patients bring forward unique values and expectations during each clinical interaction, which should be incorporated into the EBP process using clinically relevant methodologies (Sackett \& Haynes, 2002).

Research evidence alone cannot inform the best clinical decisions; rather it can support the decision-making process. Use of all three components as depicted in Figure 2 during clinical decision-making improves a patient's clinical outcomes and ultimately their quality of life (Duke University Medical Center, 2015; Fritz et al., 2007; Liddle 
et al., 2005; Overmeer et al., 2005; Rutten et al., 2010). The use of EBP by physical therapists is often driven by clinical experiences whereby questions arise in the decision-making process related to a patient's pathology, values, and prognosis.

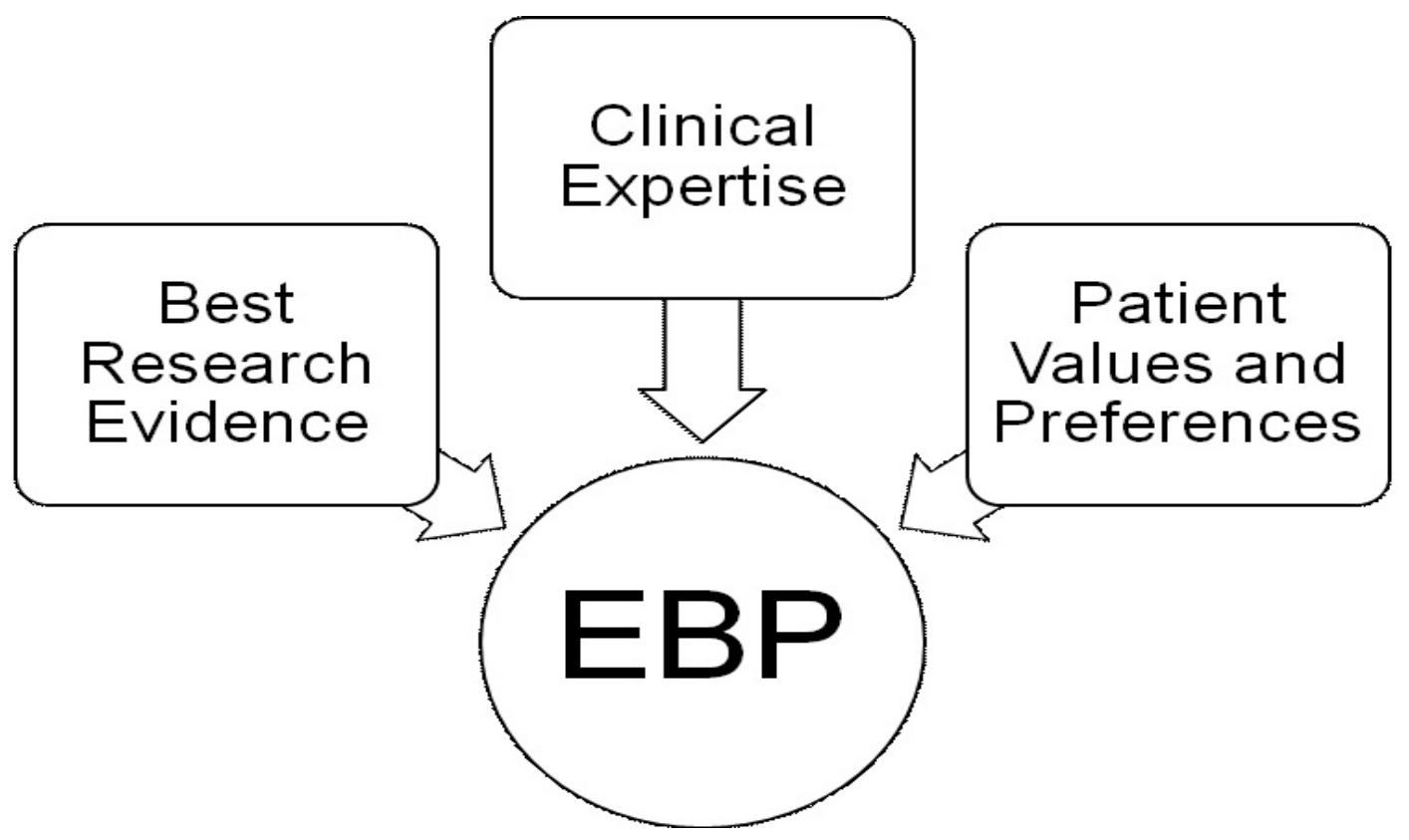

Figure 2. Evidence-based practice. Adapted from What is Evidence-Based Practice $(E B P)$ ? by Duke University Medical Center, 2015, retrieved from http://guides.mclibrary. duke.edu/print_content.php?pid=431451\&sid=3529499\&mode=g, para.

Evidence-based practice today requires a new and unique set of skills. It not only involves skills in history taking, performing an examination, and organizing the clinical decision-making process to formulate a diagnosis, prognosis and plan of care, but should also involve specific steps in the EBP process (D. U. Jette et al., 2003). These five steps were formally defined by the delegates of the International Conference of Evidence-Based Health Care in the Sicily Statement on EBP as the five core steps of EBP (Dawes et al., 2005). These core steps have been accepted internationally and are the present standard 
for curriculum in both entry-level and postprofessional physical therapist educational programs (Tilson et al., 2011). These steps are outlined in Table 1.

Table 1

The Five-Step Evidence-Based Practice Process

\begin{tabular}{cl}
\hline Step & \multicolumn{1}{c}{ Activity } \\
\hline 1 & $\begin{array}{l}\text { Ask: Translation of uncertainty into a focused searchable } \\
\text { clinical question }\end{array}$ \\
2 & $\begin{array}{l}\text { Acquire: Search for and retrieval of research evidence } \\
\text { Appraise: Critical appraisal of research evidence for validity } \\
\text { and clinical importance }\end{array}$ \\
4 & $\begin{array}{l}\text { Apply: Integration of research evidence with patient } \\
\text { perspectives and clinical expertise; application of appraised } \\
\text { evidence to practice }\end{array}$ \\
& Assess: Evaluation of performance/reflection \\
\hline
\end{tabular}

Despite the growing amount of research evidence in healthcare today, significant gaps and barriers continue to exist between the researcher and healthcare professional (Hadouda et al., 2009; Haynes \& Haines, 1998). For example, there are numerous research studies that support new and improved uses of drugs; however, there is a question about whether this research evidence ever reaches the healthcare professional, and, more importantly, the target patients. There is a lack of translation about the research in knowledge translation (KT) from the basic sciences into everyday decisions and clinical practice on the part of the healthcare professional and a significant need to study "bench-to-bedside" or the KT gap (Woolf, 2008). A clinician must be able to carry out the five-step EBP process, and, if problems arise during even one of the steps, this problem can be regarded as a barrier to the translation of EBP (D. U. Jette et al., 2003). 
Barriers related to the translation of EBP reported by health care professionals included: lack of time and lack of skills and knowledge when searching and reviewing the research evidence (Bayley et al., 2012; Bennett et al., 2003; Lewin, 1998; McCluskey, 2003; Metcalfe et al., 2001; Pollock, Legg, Langhorne, \& Sellars, 2000), poor accessibility to research evidence (Cranney, Warren, Barton, Gardner, \& Walley, 2001; Ely et al., 2002; Flores, Lee, Bauchner, \& Kastner, 2000; Kajermo, Nordström, Krusebrant, \& Björvell, 1998), perceived conflict with a patient's preferences (Freeman \& Sweeney, 2001) and organizational, environmental, and economic concerns from the workplace (Bayley et al., 2012; Cranney et al., 2001; Salbach, Jaglal, Korner-Bitensky, Rappolt, \& Davis, 2007). Although even the most contemporary definitions of EBP include information about a patients' outcomes and quality of life, there continues to be a lack of evidence from "bench-to-bedside" in terms of how KT of EBP is utilized on the part of the practicing clinician (Bayley et al., 2012; Bernhardsson \& Larsson, 2013; Woolf, 2008).

\section{Evidence-Based Practice in Physical Therapy}

Around the world, physical therapy continues to embrace EBP, and the World Confederation for Physical Therapy (WCPT) supports the highest standard of healthcare that is "underpinned by sound clinical reasoning and scientific evidence" (APTA, 2015c, para. 2). The WCPT embraces the improvement of global health through the utmost standards of physical therapy research, education and clinical practice (APTA, 2015c). The WCPT has several publications and resources, such as WCPT News, policies, and reports on EBP to further the development and assist with KT worldwide (APTA, 2015c).

In the United States, the APTA (2014b) "seeks to improve the health and quality of life of individuals in society by advancing physical therapist practice, education, and 
research, and by increasing the awareness and understanding of physical therapy's role in the nation's health care system" (para 4). The profession of physical therapy is guided both by the APTA's vision and strategic plan. The APTA's (2014b) vision statement of "transforming society by optimizing movement to improve the human experience" (para. 2) was adopted by the House of Delegates in 2013 and is further supported by eight guiding principles. The guiding principles of identity, quality, collaboration, value, innovation, consumer-centricity, access, and advocacy are used to facilitate "how the profession and society will look when this vision is achieved" (APTA, 2014b, para. 1). The APTA, like the WCPT, has numerous publications that support EBP such as Journal of Physical Therapy, and various resources such as PTNow, in addition to educational documents, and continuing education courses. The APTA fully supports EBP, as defined by Sackett and Haynes (2002), when used in alignment with the organizational vision and guiding principles.

Despite the ongoing efforts to support EBP in physical therapy, there are many aspects of clinical practice that lack research evidence to guide the decision-making process (O'Sullivan et al., 2014). Examples, where evidence is lacking, include the dose, intensity, and frequency of exercise for specific patient populations (O'Sullivan et al., 2014). Physical therapists may over and under use interventions based on anecdotal evidence (Harris, 1996). To ensure continued movement in a positive direction with regards to EBP, the APTA developed a Clinical Research Agenda (Goldstein, Elliot, \& Guccione, 2000). This agenda was recently revised in 2011 to embrace the rapid and continual changes in health care and rehabilitation (Goldstein et al., 2011) and identifies 
broad categories of research and is consistent with the International Classification of Functioning, Disability, and Health (ICF) framework.

In addition to the global initiatives of the APTA, there are more specific initiatives to further EBP within several of the specialty sections of this organization. Specialty sections of the APTA are designed for association members to further their interests and stay abreast of current topics in a specific area(s) of interest (APTA, 2015c). Presently, there are 18 specialty sections of the APTA, and each section has its own publications and resources to continue to foster EBP in conjunction with the association's vision and strategic plan (APTA, 2015c). For example, the Orthopedic Section of the APTA (2015) has recently published evidence-based clinical practice guidelines (EBCPGs) in alignment with the ICF model. Evidence-based clinical practice guidelines are defined by the Institute of Medicine as systematically developed statements to assist the practitioner with patient decisions about appropriate health care for specific clinical circumstances (Scalzitti, 2001). In addition, the Section on Research initiated and now the APTA supports a recent endeavor called PTNow. PTNow is a web-based peer reviewed portal that has clinical summaries, Cochrane reviews, clinical guidelines, and an outcome measure (OM) section, all in support of the KT (APTA, Research Section, 2014). Resources such as these, according to Rothstein (2001), are clinically meaningful because they "are not telling us what is known and what is not known, but what is supported by evidence and what is not supported by evidence" (p. 1620). Despite these tremendous initiatives to increase the number of accessible and current resources for KT, little research exists about the how this knowledge is utilized once it enters the Knowledge to Action (KTA) cycle. To date, the practice style traits of physical therapists, who are 
targeted as the primary users of these initiatives, have not been determined with regards to the second action phase, adaptation of knowledge to the local context, within the KTA cycle.

Further detail about KT and its implementation of EBP is provided by the Neurology section of the APTA. The Neurology section was the first specialty section to publish peer-reviewed recommendations for the use of outcome measures (OMs) across practice settings, referred to as Evidence Database to Guide Effectiveness or EDGE documents (APTA, Neurology Section, 2015a). Evidence Database to Guide Effectiveness documents provide data rich summaries of the psychometrics for OMs, which can lead the physical therapist to more effective OM selection based on the patient's specific goals and clinical presentation. The use of EDGE documents in clinical practice is another example of advancing the use of EBP, and a means of increasing competency and expertise for physical therapists who treat patients with neurologic disorders. Despite the wealth of knowledge available with the EDGE documents, there is a lack of research about the physical therapist's barriers, facilitators, attitudes, knowledge, behaviors, and prerequisites for $\mathrm{KT}$ as it relates to the use of OMs in clinical practice after attending an educational intervention.

\section{Guidelines for Evidence-Based Practice in Physical Therapy: Decision-Making and Conceptual Frameworks}

Physical therapists make decisions in the clinical environment which involve a multitude of factors, such as the use of cognitive skills to process information, reach decisions, and conclude the appropriate actions (O'Sullivan et al., 2014). The charge to the physical therapist is their ability to translate this knowledge during this 
multidimensional process. Clinical decision-making is regarded as an ongoing process that often occurs implicitly to assist the physical therapist with understanding and applying of evidence to meet the ongoing demands of the local or clinical environment (O’Sullivan et al., 2014).

Algorithms are often used as decision-making frameworks and act to guide the thought processes of clinical reasoning. In physical therapy, a commonly used and accepted algorithm is the Hypothesis-Oriented Algorithm for Clinicians II (HOAC II; Rothstein et al., 2003). The HOAC II is a patient-centered approach, and the physical therapist's clinical decision-making is driven by the iterative processes of generating hypotheses (Schenkman, Deutsch, \& Gill-Body, 2006). According to O'Sullivan and colleagues (2014), "Hypotheses are defined as the underlying reasons for the patient's problems, representing the therapist's conjecture as to the cause" (p. 2). When applying the HOAC II during patient management, problems are defined in terms of activity limitations, and the physical therapist works to distinguish the difference between existing and anticipated problems. Use of the HOAC II provides structure for the clinical decision-making process as the physical therapist employs EBP, and yields an outline of decisions made (O'Sullivan et al., 2014). Despite the widespread knowledge of the HOAC II for clinical decision- making, little research evidence exists about how this conceptual framework is translated into clinical practice and adapted to the local context (action phase 2) within the KTA cycle.

There are additional frameworks that assist with the physical therapists' clinical decision-making. The World Health Organization's (WHO's) ICF Model of Disability, which was adopted by the APTA and WCPT in 2008, provides a critical framework and 
classification of terms that work to define and categorize a patient's problems and the impact of a health condition (WHO, 2002). The ICF framework has specific definitions of how a patient's health condition can impact the three domains of body functions and structure, activity, and participation. Figure 3 is the ICF Model of Disability.

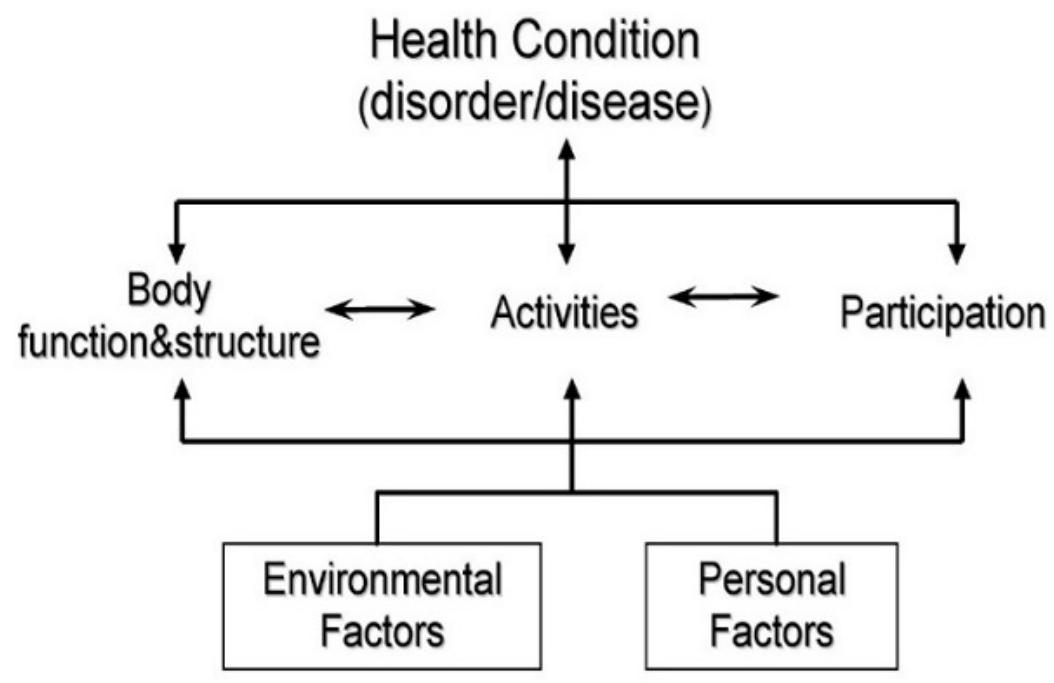

Figure 3. ICF framework. Adapted from Physical Rehabilitation (6th ed.), by S. B. O’Sullivan, T. J. Schmitz, and G. Fulk, 2014, Philadelphia, PA: F. A. Davis, p. 23.

According to O'Sullivan et al. (2014):

Impairments are the problems a patient may have within their body function (physiological function of body systems) or structure (anatomical parts of the body). The resulting significant deviation of loss is the direct result of the health condition, a disease, disorder, injury, or trauma, or other circumstance, such as aging. (p. 2)

Examples of impairments that may impact the body functions and structure domain are muscle weakness, apraxia, and sensory loss. 
The second of the three core domains of the ICF is that of activity. When problems arise in this domain, patients have limitations in completing functional tasks and limitations with the cognitive and learning abilities to execute a functional task. Examples of activity limitations for a person who has suffered a stroke could include self-care activities, such as dressing and transfers and mobility required for activities such as eating and bathing (O'Sullivan et al., 2014).

The third core domain of the ICF involves that of participation. Participation restrictions are those that impact a patient's societal roles and impact an individual's personal everyday life. Participation restrictions for an individual who has a health condition of stroke could include not being able to go to their work, being unable to golf, and unable to dance with their spouse (O'Sullivan et al., 2014).

The ICF Model of Disability also includes the contextual elements of environmental and personal factors. These factors represent a patient's life and living situation. They assist with the identification of both performance and capacity qualifiers to further define a person's activity limitations and participation restrictions (O'Sullivan et al., 2014). Performance qualifiers involve all aspects of the social and physical world and help the extent of difficulty when performing a task. Capacity qualifiers are used to quantify the extent of a patient's activity limitations. In stroke, the performance qualifiers could include decreased ambulation in the home environment and the use of an assistive or orthotic device (O'Sullivan et al., 2014). In understanding and applying the ICF framework to clinical practice, the clinician must remember that the environmental factors cover a wide range, which include "physical, social, and attitudinal environment in which people live and conduct their lives, including social attitudes, architectural 
characteristics, and legal and social structures" (O’Sullivan et al., 2014, p. 2). Lastly, a clinician must appreciate that personal factors involve all of the aspects of their patient's lives to include their: behavior, personality, past and current experience, gender, age, coping styles, social background, and educational level (O'Sullivan et al., 2014).

In physical therapy, both the HOAC II and the ICF Model of Disability assist with the clinical decision-making and allow the practicing clinician to not only incorporate all physiological, psychological, and societal aspects of their patients, but also these frameworks embrace the use of EBP. An additional framework which is also a component of the decision-making process is the Guide to Physical Therapist Practice, 3rd edition (APTA, 2014a). Moving forward in this dissertation the Guide to Physical Therapist Practice will simply be called the Guide. The Guide was developed to assist in defining the profession, to create a uniform approach to patient care, and identify a universal framework that is conceptual in nature, which embraces EBP and use of the ICF (APTA, 2014a). According to the Guide, the framework used for clinical practice involves a patient management system with six steps. These steps include: examination of the patient, evaluation of the data and identification of the problems, determination of the physical therapy diagnosis, determination of the prognosis and plan of care (POC), implementation of the POC and reexamination of the patient and evaluation of treatment outcomes (APTA, 2014a). The steps of the patient management system according to the Guide are depicted in Figure 4.

The Guide, like the HOAC II and ICF framework, provides a strong conceptual background and supports EBP throughout the decision-making process (APTA, 2014a). Despite this support, little research evidence is available about the behaviors and traits of 
physical therapists that make the clinical decisions and the extent to which KT is occurring during the patient management system.

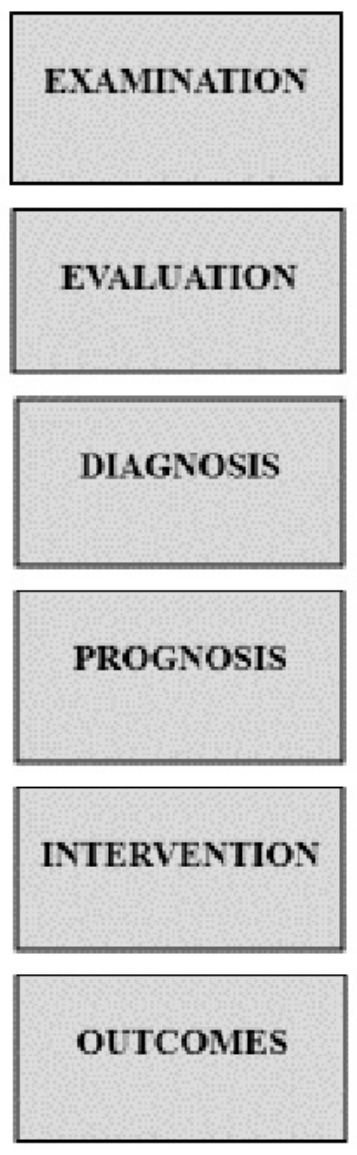

Figure 4. Elements of the patient/client management system. Adapted from Guide to Physical Therapist Practice (3rd ed.), by the American Physical Therapy Association (APTA), 2014a, Alexandria, VA: Author, retrieved from http://guidetoptpractice. apta.org/content/1/SEC2.body\#F6

\section{Definition and Application of Standardized Outcome Measures}

Outcome measures are specific types of tests and measures used in the patient management process to measure various constructs related to a patient's health condition (Potter et al., 2011). Physical therapists, like many other health care professionals, have written about the various benefits of using OMs for many years (Deyo \& Carter, 1992; 
Deyo \& Patrick, 1989; Garland, Kruse, \& Aarons, 2003; Lansky, Butler, \& Waller, 1992; Nelson \& Berwick, 1989). The reported reasons for using OMs include: to assist in the identification of patients who may be at risk of adverse conditions (Lansky et al., 1992) and improve communication across the health care team and with third party payers, particularly as patients transition their care across practice settings (Kramer \& Holthaus, 2006). When OMs are applied in the clinical setting, they can assist with determining the most efficient and cost-effective interventions based on both individual physical therapist and organizational performance by tracking a patient's progress over time (Lansky et al., 1992).

In physical therapy, use of OMs has been identified and mandated at the national level in the United States. The Centers for Medicare and Medicaid Services (CMS) in 2006 requested the use of OMs to be used across rehabilitation settings to capture a patient's status upon leaving the acute care setting (Kramer \& Holthaus, 2006). In 2012, as part of the Middle-Class Tax Relief Act, CMS required that physical therapists report on the functional limitations of their patients. Beginning July 1, 2013, physical therapists were required to report these functional limitations using OMs, otherwise known as the G-code reporting system (CMS, 2015). The intent was to use these data for future reform of the reimbursement of services rendered by a physical therapist. To support the national initiatives, the Commission on Accreditation in Physical Therapy Education (CAPTE) supports the use of OMs by now requiring inclusion of OMs within entry-level physical therapy education. Teaching, as defined by CAPTE, includes introduction, demonstration, application, and documentation of OMs across the various health conditions and practice settings (CAPTE, 2006). Specialty sections of the APTA, like 
the Neurology Section, continue to lead the profession by incorporating the use and translation of OMs in their strategic plan and goals (Neurology Section, 2015). These initiatives have been discussed in the prior sections titled EBP in physical therapy.

Within the patient management framework outlined in the Guide, the driving force to use OMs is about gathering data about a patient's actual or perceived abilities when moving in their environment using the ICF Model of Disability. Still measured, however often to a lesser degree, are OMs that gather data as they relate to the body functions and structure domain of the ICF (impairments) (Haigh et al., 2001; D. U. Jette et al., 2009). Outcome measures, according to D. U. Jette and colleagues (2009), “[A]re standardized in that they use closed-ended questionnaire formats or specific protocols for implementation, provide scores that allow quantitative assessment of ability, and have been evaluated for their psychometric properties" (p. 126).

Examples of OMs in the activity domain of the ICF are the Dynamic Gait Index (DGI), which captures a patient's ability to walk under dynamic conditions and with external demands, and the Berg Balance Scale (BBS), which measures static, anticipatory balance of adults who may be at risk of falling (O'Sullivan et al., 2014). Participation OMs include a variety of patient questionnaires, such as the Stroke Impact Scale (SIS), which assesses a patient's health status following a stroke, and the Dizziness Handicap Inventory (DHI), which is designed to capture a patient's self-reported level of handicap caused by their dizziness (O'Sullivan et al., 2014). Lastly, examples of body functions and structures OMs are the Stroke Rehabilitation Assessment of Movement (STREAM) and the Fugl-Meyer Assessment (FMA), which were both designed to quantitatively measure a patient's motor function following a stroke (Potter et al., 2011). 
Knowledge translation of OMs is an essential component of EBP in physical therapy because they use the best available evidence to optimize patient care. When used during the patient management framework, OMs vary considerably from the more traditional tests and measures, such as range of motion or manual muscle testing. For example, when a physical therapist observes a patient's posture and movement and amount of muscle tone, these data can be compared to the evidence in terms of what is considered "normal"; however, it does not take into account the changes in a patient's health status and performance over time (D. U. Jette et al., 2009; Potter et al., 2011). Because both health status and performance have numerous variables that define these constructs, the use of OMs acts to capture these components and further impact the human experience.

Outcome measures can be used during the various steps of the patient management framework. For example, when used during the initial examination, the goal is to support and enhance the physical therapist's decision-making processes. During the examination, the physical therapist should use selected OMs to drive the POC and documentation of patient-specific goals (Haigh et al., 2001; D. U. Jette et al., 2009). Outcome measures can also be incorporated with subsequent revisions of the POC and at the end of care in preparation for discharge to allow determination of the change over a certain period of time (D. U. Jette et al., 2003; Potter et al., 2011). Lastly, and most importantly, because OMs serve to measure patient change over time, they should be considered a required component to measure treatment efficacy (Fulk \& Field-Fote, 2011). In line with the mission and vision of the APTA, a physical therapist's duty is to use OMs based on a patient's unique presentation of their body structure/function, 
activities, and participation domains to identify evidence-based interventions that will result in optimal patient recovery (Fulk \& Field-Fote, 2011). Despite employing the best possible evidence-based interventions, for example to the same motor dysfunction, the research evidence does not always allow us to determine which interventions are superior to others (Fulk \& Field-Fote, 2011). In physical therapy, there needs to be continued emphasis placed on accumulating an increased amount of data to support a particular intervention with a particular patient in a specific treatment setting or context. Because the effectiveness of intervention is so critical for restoring a patient's optimal recovery, using OMs across the domains of the ICF Model of Disability is a significant step in KT. Ultimately, selecting the best OMs for each patient's unique situation will allow for optimal comparisons across patients, interventions, and clinicians. It is critical that physical therapists use a common set of OMs that are reliable, valid, responsive to change, and reflect clinically important outcomes (Fulk \& Field-Fote, 2011).

The body of evidence that supports OMs has grown considerably, and the key to using and applying OMs is to determine whether change constitutes important change and whether real change has taken place as a result of treatment (Beninato \& Portney, 2011). Several psychometric properties, in addition to the more standard indices of reliability, validity, sensitivity, and specificity, have been identified. Significant psychometric properties reflecting an OMs ability to capture true change include minimal detectable change (MDC) and minimally clinically important difference (MCID). Collectively, these measures are important characteristics of validity and are often termed measures of responsiveness (Beninato \& Portney, 2011). These indices are derived from clinical measures and used to enhance the interpretability of change scores. Accurate 
interpretation and application of these indices are crucial to informed patient management and the clinical decision-making process (Aarons, Ehrhart, Farahnak, \& Sklar, 2014; Fulk \& Field-Fote, 2011).

An example of how the use of OMs can enhance the patient-centered and EBP approach can be applied to a patient who has sustained a stroke. If an individual has had a stroke and is medically safe to transition to an inpatient rehabilitation facility, a physical therapist, as part of the initial examination would think critically and apply the decision-making process to select OMs focused on balance and gait (Beninato \& Portney, 2011; Potter et al., 2011; Sullivan et al., 2011). Outcome measure selection would be based on using the frameworks of the Guide, HOAC II, and ICF Model of Disability to ensure measure selection that both qualitatively and quantitatively capture the patient's impairments, activity limitations, and participation restrictions. When completing the POC, the physical therapist would establish goals based on the evidence that is supported by the measures of responsiveness. Using both MDC and MCID can assist in determining if both true and important change has occurred. More specifically, if the BBS were used to assess static, anticipatory balance and the initial score was a 35 for the patient who sustained a stroke, this would then be reassessed in approximately 2 weeks. If the new score was a 41 , this change of 6 points would be compared to the MDC for the BBS. Based on the work of Stevenson (2001), the MDC was determined to be 7 points for the BBS and, in the case of the example above, the 6-point change would not be considered true change, as it did not exceed the MDC or measurement error (Potter et al., 2011). 
Despite the importance of EBP initiatives and the mandate from CMS to use OMs, OM selection, usability (Herbert, Jamtvedt, Mead, \& Hagen, 2005; A. M. Jette \& Haley, 2005), and translation into and across practice settings remains limited (D. U. Jette et al., 2009; Van Peppen, Maissan, Van Genderen, Van Dolder, \& Van Meeteren, 2008). Limitations for lack of KT of OMs include barriers of measure selection in attempting to use the various frameworks of clinical practice (Huijbregts, Myers, Kay, \& Gavin, 2002), time constraints, lack of knowledge, and equipment (D. U. Jette et al., 2009; Kay, Myers, \& Huijbregts, 2001; Van Peppen et al., 2008). To date, little research has been done to determine if a targeted educational intervention on OMs would improve KT into clinical practice. In addition, there is little to no research in terms determining a physical therapist's practice style trait and its ability to predict their barriers, facilitators, attitudes, knowledge, behaviors, and prerequisites for KT as action phases within the KTA cycle.

The conceptual framework underlying this educational dissertation is based on Ian Graham's model of KT and the KTA cycle (Graham et al., 2006; Straus et al., 2013). This dissertation will test hypotheses and generate further knowledge as it relates to three specific action phases in the KTA cycle: action phase 2-adaptation of knowledge to the local context, action phase 3-barriers and facilitators to knowledge use, and action phase 5-monitoring knowledge use (Straus et al., 2013). The theoretical orientation of this dissertation is supported by both the cognitive psychology and educational theories (Straus et al., 2013) (see Figure 5). 


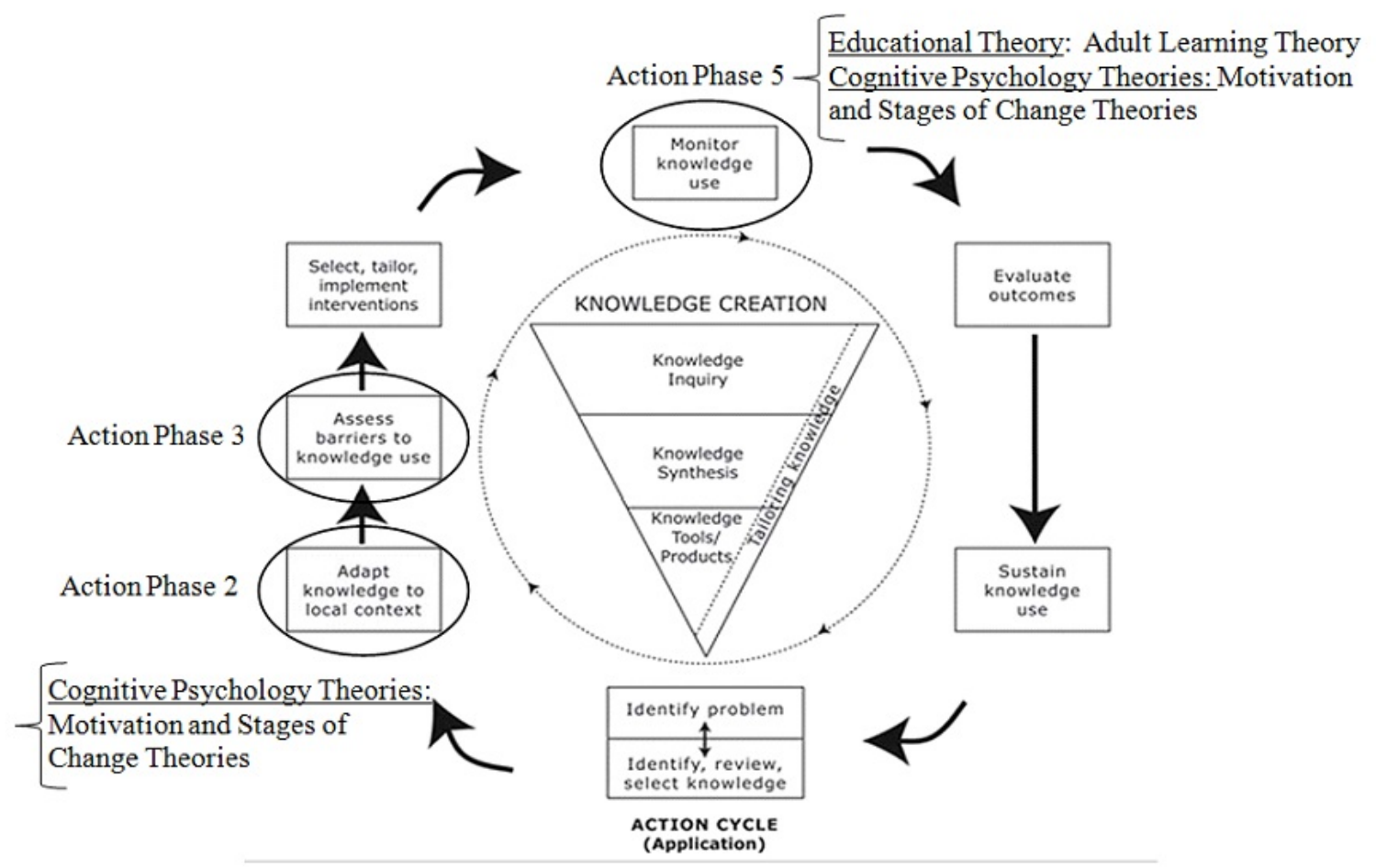

Figure 5. Knowledge to Action (KTA) cycle with supporting theoretical orientation. Adapted from "Lost in Knowledge Translation: Time for a Map?" by I. D. Graham, J. Logan, M. B. Harrison, S. E. Straus, J. Tetroe, W. Caswell, and N. Robinson, 2006, Journal of Continuing Education in the Health Professions, 26(1), p. 19.

There are several cognitive psychology theories that have a significant impact in the field of KT and KTA and help inform this dissertation framework. These theories are related to motivation and to stages of change (Straus et al., 2013). These theories support action phase 2-adaptation of knowledge to the local context, action phase 3-assessing barriers to knowledge use, and action phase 5-monitoring knowledge use within the KTA cycle. Theories related to motivation and those related to stages of change provide a framework for examining, measuring, and understanding behaviors in KT and the KTA cycle (Straus et al., 2013). Current KT scholars have developed a line of inquiry that applies cognitive psychology theories to their research questions, which then guides the 
specific interventions that strategically influences uptake and adoption of EBP (Straus et al., 2013). In this dissertation, the researcher is following the premise supported by KT and KTA frameworks that a physical therapist's behavior regarding the use of evidence is within the therapist's control. These frameworks support social cognitive aspects including beliefs, knowledge, and attitudes that are considered to be more receptive to change than aspects of personality (Straus et al., 2013). Attending an educational intervention related to EBP and the use of OMs could then influence these cognitive characteristics of the physical therapist and, therefore, may modify their behavior (Conner \& Norman, 2005).

The first cognitive psychology theory of motivation believes "behavior is determined and, therefore, predicted by motivation" (Straus et al., 2013, p. 289). Two specific motivational theories, which are tested and supported by this dissertation, are social-cognitive theory of self-efficacy and the theory of planned behavior (Jensen, 2011; Straus et al., 2013). According to Bandura (as cited in Straus et al., 2013), social cognitive theory is a powerful motivational theory that assumes that behavior is determined by incentives and expectations related to situation-outcomes (beliefs about anticipated consequences if the individual abstains from the respective behavior); action-outcomes (beliefs about the likelihood of certain outcomes occurring as a result of the behavior); and perceived self-efficacy (beliefs about the extent to which the behavior is within the individual's control). (p. 289)

Bandura $(1977,1982)$ theorizes that there are four sources of knowledge that influence self-efficacy and a person's expectations. These sources of knowledge include: 
performance accomplishments, experience learned through others, social persuasion, and the physiological and emotional state of the individual. Bandura believes that performance accomplishments are the most powerful source of information and result in significantly impacting both professional and personal experience (Straus et al., 2013). Observing the behavior and accomplishments of others, such as mentors, opinion leaders, and role models, is an example of learning through others. Engagement in an academic setting and continuing education are examples of how verbal persuasion involves "nurturing individuals' self-confidence in their ability to accomplish a specific behavior and persuading them of the benefits of that behavior" (Straus et al., 2013, p. 289). Lastly, Bandura theorizes that feedback as a result of a certain behavior is the least influential of the theories related to self-efficacy and one's expectations (Straus et al., 2013).

Because the social cognitive theory of self-efficacy affects the choice of activities, for example, continuing education, and the individual's persistence and effort, self-efficacy can be directly linked to the specific action phases within the KTA cycle. Action phase 2-adaptation of knowledge to the local clinical environment - can involve an individual who self-selects to attend a continuing education course and while in attendance would experience social persuasion, use of past knowledge and experience, and learning through others. These sources of self-efficacy could then impact the behavior and performance of the participant who attended the continuing education course. Also, this theory can be applied to action phase 3-assessing barriers to knowledge use as the sources of self-efficacy — will help determine the barriers to using knowledge after attending a continuing education course. In addition, self-efficacy can be reflected in action phase 5-monitoring knowledge use as the sources to drive behavior 
change - all relate to performance accomplishments and use of experience learned through others when considering the use of EBP in the form of OMs in daily practice (Straus et al., 2013). The theory of self-efficacy and the supported decisions that are made regarding the behaviors of EBP have not been studied to date in terms of how a physical therapist alters behavior after attending an educational intervention specific to the application of OMs in clinical practice. There are limited reports in the literature about the perceived barriers, facilitators, attitudes, knowledge, behaviors, and prerequisites of physical therapists as related to the social cognitive theory of self-efficacy (Bernhardsson \& Larsson, 2013; Straus et al., 2013) (see Figure 6).

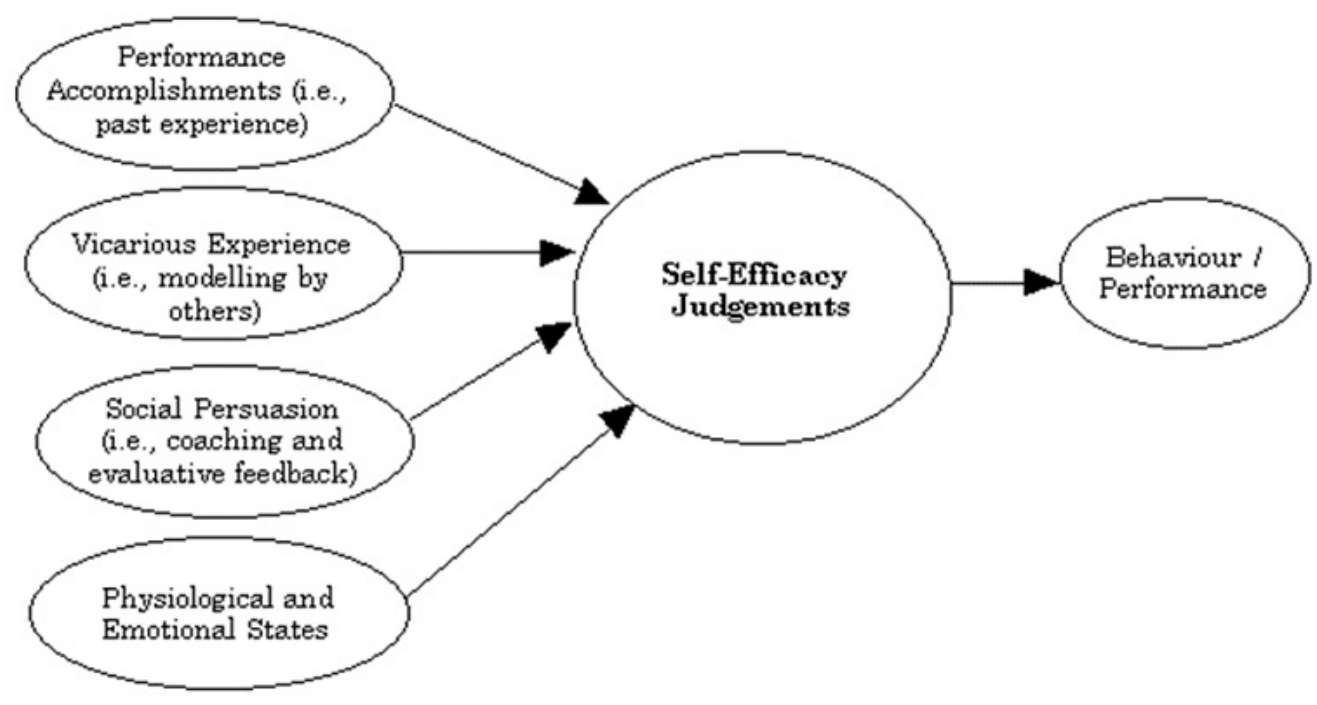

Figure 6. Sources of self-efficacy information. Adapted from Bandura and Self Efficacy, by MELLBandura, 2015, retrieved from http://mellbandura.wikispaces. com/Bandura+and+Self+Efficacy, para 2.

The second motivational theory, on which this dissertation is based, is the theory of planned behavior. This theory can be used to understand how individuals' behavior can change over time. This theory, originally described by Ajzen (1991) and pictured in 
Figure 7, states that behavior can be predicted based on the intention to engage in and perceived control over one's behavior. The three constructs involved with this theory are attitudes, subjective norms, and behavioral control (Ajzen, 1991). Attitudes about the behavior refer to the beliefs about the likely consequences of the behavior, and subjective norms refer to the beliefs about the normative expectations of others. The third construct on which the theory of planned behavior is based is that of perceived behavior control that refers to a belief about the presence of factors that may influence or impede performance of the behavior (Ajzen, 1991, 2005).

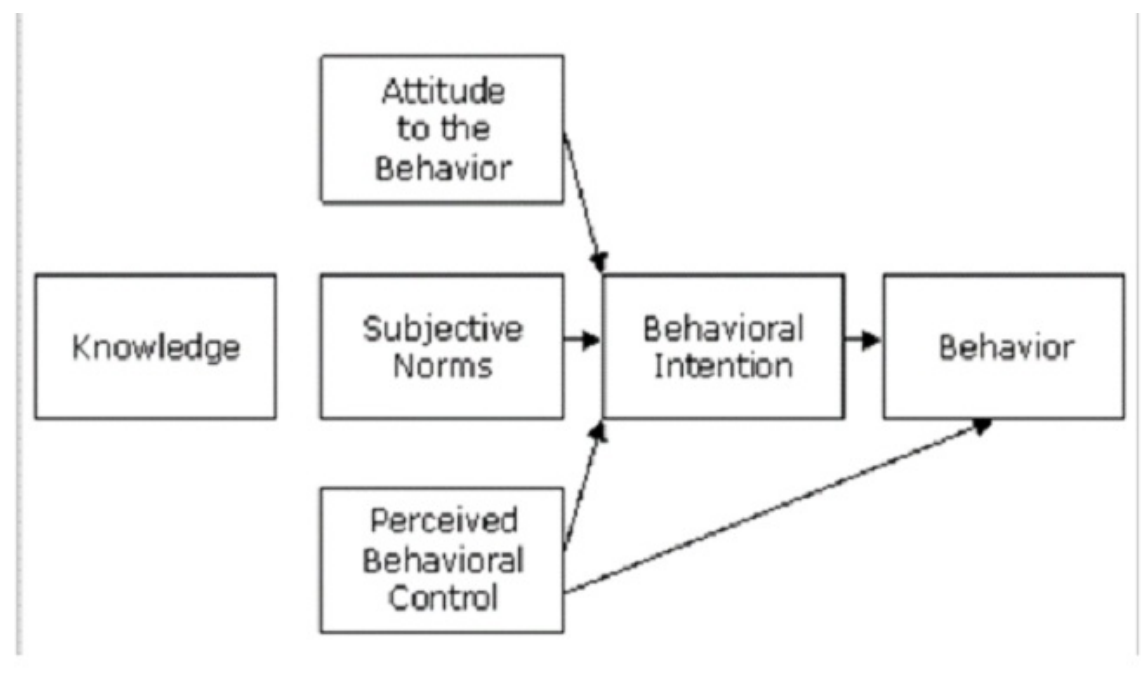

Figure 7. Theory of planned behavior. Adapted from Summary of the TPB by Adzen-Abstract, by Value Based Management.net, 2014, retrieved from http://www.valuebasedmanagement.net/ methods_ajzen_theory_planned_behaviour.html

Straus and colleagues (2013) have similar beliefs about Ajzen's original theory of planned behavior and theorizes that the intentions of one's behavior are a function of one's attitude and are determined by the potential consequences of the behavior. Intention is also influenced by constructs of group norms that are opinions of others with 
respect to the behavior and are balanced against one's desire to comply with the expected predictions of a particular group (Straus et al., 2013). In a healthcare setting, a physical therapists' behavior to make clinical decisions may be influenced by their peers, managers, and patients. Lastly, the theory of planned behavior describes behavioral control, which comes from the motivational aspects of social cognitive theory and believes that behavior is balanced between both positive and negative influences, such as access to resources, equipment, and time in terms of how the healthcare professional pursues a particular course of action (Straus et al., 2013).

Motivational theories, such as social cognitive theory of self-efficacy and theory of planned behavior, have been used in a variety of studies to predict the utilization of specific research evidence by healthcare professionals such as physicians and nurses (Eccles et al., 2007; Perkins et al., 2007). Researchers believe that the three constructs of attitudes, subjective norms, and behavioral control of the theory of planned behavior offer support for the development of interventions that influence behavior (Eccles et al., 2007; Perkins et al., 2007). For example, in healthcare educational interventions could be designed to promote KT of EBCPGs and would therefore include addressing barriers to implementation, negative attitudes toward the use of, and specific skills and training to enhance a clinicians' confidence for KT (Straus et al., 2013). With primary care physicians, both the theory of planned behavior and social cognitive theory of self-efficacy have been used to develop specific interventions to encourage the behavior of not prescribing antibiotics for patients who have sore throats through the use of EBCPGs and case-based scenarios (Hrisos et al., 2008a, 2008b). Further research specific to the theory of planned behavior has been used in randomized trials related to 
KT strategies to guide the process evaluation whereby physicians test-requiring behavior was highly correlated with the constructs of this theory (Ramsay, Thomas, Croal, Grimshaw, \& Eccles, 2010). The theory of planned behavior and its constructs are useful to guide process evaluations to better understand the causal relationships between KT and adoption of a specific intervention; however, to date these theories and constructs have not been applied to specific action phases within the KTA cycle specific to physical therapists as the healthcare practitioner (Ramsay et al., 2010).

The second cognitive psychology theory that informs this dissertation is the stages of change theory; specifically, the transtheoretical model of change. The transtheoretical model of change supports how an individual and their behavior can change and progress over time and is defined by five specific stages of change as depicted in Figure 8 (Prochaska \& Velicer, 1997).

The first stage is the precontemplation stage. Here, the individual does not plan to alter their current behavior in the near future. The second stage is contemplation, where an individual plans to adopt a new behavior within 6 months (Prochaska \& Velicer, 1997). The transition from precontemplation to the contemplation stage may involve the use of such strategies as continuing education and educational interventions that change knowledge or an individuals' attitude (Cohen, Halvorson, \& Gosselink, 1994). The third stage of preparation involves the individual adopting the behavior within the next month.

The action stage is the fourth stage, where an individual has adopted the new behavior from the previous 6 months (Prochaska \& Velicer, 1997). Movement along the continuum from contemplation to preparation and eventually to action stages requires alterations in self-efficacy and for an individual to self-reflect on their particular 


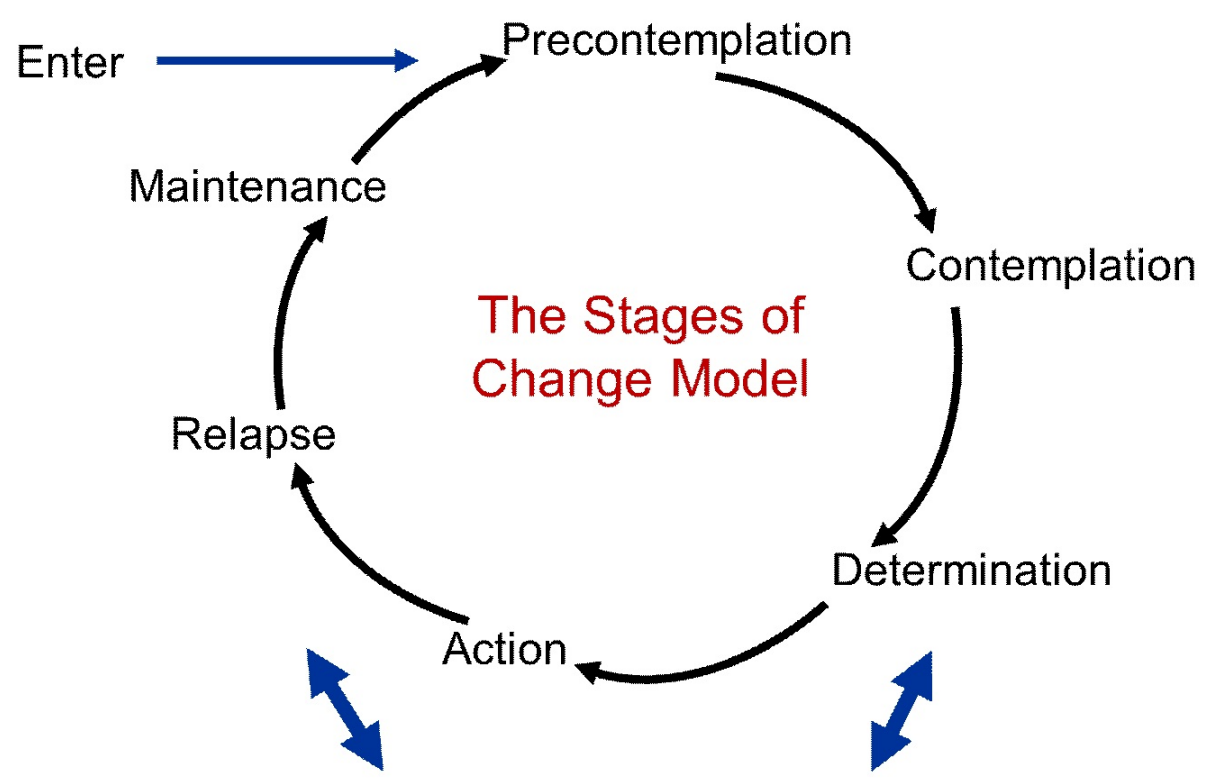

Exit \& re-enter at any stage

Figure 8. Transtheoretical model (stages of change). Adapted from Behavioral Change Models, by the Boston University School of Public Health, 2013, retrieved from http://sphweb.bumc.bu.edu/otlt/MPHModules/SB/SB721-Models/SB721-Models.html, p. 6.

behaviors in order for a real change to occur (Straus et al., 2013). The action stage requires support - for example, having access to the necessary equipment in order to adhere to the new the behavior. The fifth stage in the transtheoretical model of change is the maintenance stage and involves an active effort on the part of the individual to maintain the change. The final stage is the termination stage, and this is truly achieved when an individuals' behavior is "entrenched," and the individual is entirely confident of their self-efficacy in their ability to execute the behavior (Straus et al., 2013). The action, maintenance, and termination stages are achieved when the behavior change is supported by the environment, such as performing chart audits and providing ongoing feedback (Cohen et al., 1994). An important assumption of the transtheoretical model of change is 
that interventions that are targeted at an individual's specific stage will foster progression along the continuum (Prochaska \& Velicer, 1997).

The stages of change theory, specifically the transtheoretical model of change, can be linked to the KTA cycle in terms of understanding how knowledge is adapted to the local clinical environment-action phase 2 , understanding barriers to knowledge use-action phase 3, and how knowledge is applied and monitored over time-action phase 5 (Straus et al., 2013). Depending on what stage in which a physical therapist can presently practicing in can determine how they might progress over time when faced with new knowledge and EBP. This theory can be considered when planning educational interventions so that barriers to KT and EBP can be addressed to the individual learner's educational needs (Weinstein, Lyon, Sandman, \& Cuite, 1998). At present, there is a lack of research evidence about the present stage of the physical therapist's practice behaviors seeking an educational intervention. The present stage can be best described by determining the practice style traits of a physical therapist and then further applying their traits to the KTA cycle.

In a systematic review published by Godin, Bélanger-Gravel, Eccles, and Grimshaw (2008), it was concluded that cognitive psychology theory, specific to motivation theory of planned behavior, was the theory most able to predict behavior among healthcare professionals. Predicting behavior of a healthcare professional can provide insight in terms of who are likely to be the greatest users of knowledge and further application of knowledge in the KTA cycle. In a review by Bonetti and colleagues (2010) of motivational theories and stages of change theory, behavior intention and clinical decision-making were examined using clinical scenarios. The purpose of 
examining behavior intention and clinical decision-making was to predict a health professionals' application of research in their clinical setting. In the latter review, the variance in clinical decision-making and behavioral intention was significantly supported by the theory of planned behavior and the social cognitive theories (Bonetti et al., 2010). The two studies above have allowed researchers to conclude that cognitive psychology theories can be useful to predict the behavior of healthcare professionals (Bonetti et al., 2010; Godin et al., 2008).

Despite the growing body of research evidence about predicting behaviors of healthcare professionals, limitations do exist. Potential limitations of cognitive psychology theories include the failure to consider external factors, such as the environment or local context and the organizational structure in which a healthcare professional practices on a daily basis (Straus et al., 2013). Additionally, there is limited research about predicting behaviors when the focus is on the physical therapist as the healthcare professional. Most importantly, a gap in the research remains about how action phase 2-adaptation of knowledge to the local context, action phase 3-assessing barriers to knowledge use, and action phase 5-monitoring knowledge, when supported by the theories, are applied to predict the behavior of the physical therapist who has attended an evidence-based continuing education course on the application of OMs (Bernhardsson \& Larsson, 2013; Straus et al., 2013).

The educational theories, which are supported in this dissertation, are centered on Ian Graham's model of KT and specific to action phase 5-monitoring knowledge use within the KTA cycle. Educational theories can be applied to the learners' educational interventions where there are knowledge deficits centered on specific research evidence 
(Straus et al., 2013). These theories can help us understand a clinicians' ability to learn, understand, and apply the evidence into clinical practice (Straus et al., 2013). Educational theories can be used to describe the effectiveness of an educational intervention and to help design educational frameworks for testing new educational interventions (Jensen, 2011; Laidley \& Braddock III, 2000). There are a number of educational theories that can guide educational interventions; however, the theories described in the preceding paragraphs are theories that foster KT—moving knowledge into action (Straus et al., 2013) specific to action phase 5-monitoring knowledge use after attending a continuing education course for physical therapists specific to OMs.

Before discussing specific educational theories, it should be first understood that educational taxonomy, as defined by Bloom and Krathwohl (1956), as well as an individuals' learning style, should also be considered. These two principles can guide the individual learner and shape the development of future educational interventions to move knowledge into action (Straus et al., 2013). Educational taxonomy is defined by theorists to include cognitive, affective, and psychomotor domains (Krathwohl, 2002; Stuart, Tondora, \& Hoge, 2004). In health professional education, the first or cognitive domain encompasses the acquisition of academic knowledge accomplished by teaching methods aimed at the delivery of knowledge. Examples of an educational intervention using the cognitive domain include traditional lectures and use of computer-based modules (Stuart et al., 2004). The second domain is the affective domain that involves the adoption of attitudes, values, and beliefs, which are critical for a future change in an individuals' behavior. Examples of teaching strategies targeted to the affective domain include use of clinical cases, group projects/presentations, role-playing and group simulation (Stuart 
et al., 2004). The third and final domain is the psychomotor domain defined as development of skill acquisition (Bloom \& Krathwohl, 1956). Examples of this domain include being supervised by another healthcare professional so that performance can be practiced until mastery of specific skills is achieved (Straus et al., 2013). It is critical in an educational and academic curriculum that these three domains be carefully considered to optimize the learners' acquisition of knowledge and impact their clinical decisionmaking abilities that will ultimately foster KT for the betterment of patient outcomes. Another important principle that should be considered when designing an educational intervention is an individual's learning style. A wide range of learning styles exists among health care professionals (Straus et al., 2013). They have been described as activist, reflective, theoretical and pragmatic styles (Grol, Bosch, Hulscher, Eccles, \& Wensing, 2007; Lewis \& Bolden, 1989). The work of Green and colleagues (2002) and Green, Wyszewianski, Lowery, Kowalski, and Krein (2007) expands on these learning styles to define how an individual responds to new knowledge based on three theoretical constructs. Green and colleagues use the terms of seekers, receptives, traditionalists, and pragmatists. A seeker is defined as someone who considers systematically gathered research data as the most reliable source of information. Seekers make evidenceinformed decisions even if it varies from the context of their local, clinical environment, and this is measured using the theoretical construct of nonconformity (Green et al., 2002; Green et al., 2007). A seeker, who will score high in the area of nonconformity, is least likely to go along with the norms of the clinical practice environment. Similar to seekers, receptives are considered "evidence-oriented, but generally rely on the judgment of respected persons in their field for critical appraisal of new information" (Green et al., 
2002, p. 939). The third learning style are the traditionalists who view both clinical experience and authority as the most reliable sources of evidence to make clinical decisions (Green et al., 2002; Green et al., 2007). A traditionalist places the greatest value on their personal experience and the teachings of clinical leaders to guide their decisions (Green et al., 2002; Green et al., 2007). The final practice trait defined by Green and colleagues is pragmatists. Pragmatists make their clinical decisions based on time. They focus on the day-to-day efficiency and are only willing to diverge from their usual practice if it impacts time and workload in a positive manner (Green et al., 2002; Green et al., 2007). The learning styles, or practice style traits are summarized in Table 2. Also, a pictorial representation of the practice style traits can be found in Figure 9. Understanding an individual's learning style is critical to maximizing the KT into clinical practice and should be considered when educational interventions are designed and implemented (Straus et al., 2013).

There are a wide range of educational learning theories that support KT and KTA as a conceptual framework (Merriam, Caffarella, \& Baumgartner, 2012); however, specific to this dissertation only the humanist approaches will be discussed as it relates to action phase 5-monitoring knowledge use within the KTA cycle. Humanist theorists believe "learning is a function of growth; humans have control over their future, will actively work towards improvement, and have unlimited learning potential" (Straus et al., 2013, p. 301). The humanist approach focuses on individual autonomy and responsibility, whereby learning occurs through experience (Merriam et al., 2012). Benner's (1984) work with the nursing profession is concentrated around the intuitive-humanistic paradigm and views the importance of skill acquisition to understand 
Table 2

Summary of Practice Style Traits

\begin{tabular}{|c|c|c|c|}
\hline Practice style trait & $\begin{array}{l}\text { Use of evidence vs. experience in } \\
\text { local, clinical environment }\end{array}$ & $\begin{array}{l}\text { Nonconformity with } \\
\text { local, clinical } \\
\text { environment }\end{array}$ & $\begin{array}{l}\text { Practicality in } \\
\text { managing workload }\end{array}$ \\
\hline Seekers & $\begin{array}{l}\text { Extreme evidence end; evidence is } \\
\text { most reliable source of data }\end{array}$ & High & Not high \\
\hline Receptives & $\begin{array}{l}\text { Toward evidence end; evidence } \\
\text { oriented but rely on others to } \\
\text { critically appraise new data }\end{array}$ & Moderate & Not high \\
\hline Traditionalists & $\begin{array}{l}\text { Toward experience end; greatest } \\
\text { value lies with personal experience }\end{array}$ & Variable & Not high \\
\hline Pragmatists & $\begin{array}{l}\text { Variable between evidence and } \\
\text { experience; clinical decisions are } \\
\text { made based on time }\end{array}$ & Variable & High \\
\hline
\end{tabular}

Evidence versus Experience in Local, Clinical Environment

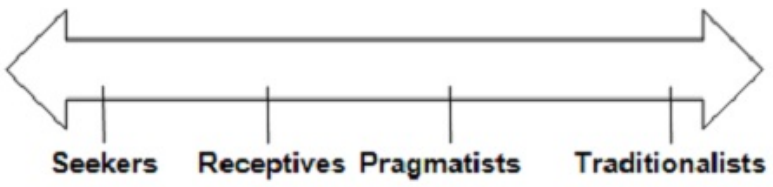

Nonconformity with Local, Clinical Environment Note: Traditionalists and Pragmatists are Both Variable

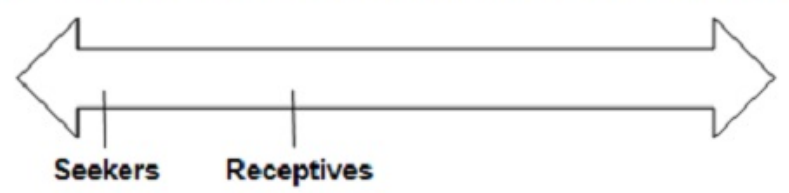

\section{Practicality in Managing Workload}

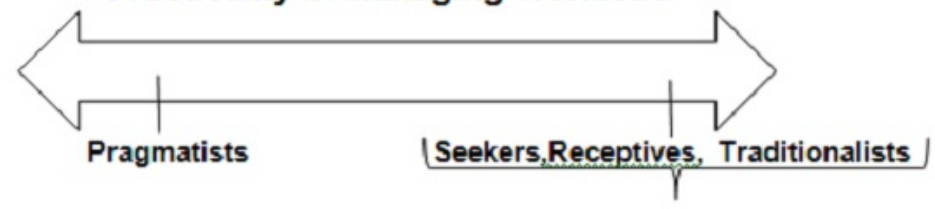

Figure 9. Pictorial representation of practice style traits. 
how nurses learn. In this model, the learner moves through a series of five stages that include: novice, advanced beginner, competent, proficient, and expert. The belief is that with the combination of knowledge and extensive clinical experience, a clinician can reach the level of expert; however, this theory has not been formally tested with physical therapists as the healthcare professional (Benner, 1984).

One of the most important theories within the humanist approach is adult learning theory. Knowles $(1970,1980)$ is most well-known for defining adult learning theory, whereby he proposed specific principles that can be used to design educational interventions. These principles are outlined below.

- Adults are self-directed: they need to decide what they want to learn.

- Adults have acquired a range of experiences and learning can be more meaningful when prior knowledge can be integrated with new knowledge.

- Adults are goal directed: encountering situations that require certain knowledge stimulates readiness to learn.

- Adults are relevance-oriented: they require new knowledge to be relevant.

- Adults focus on acquiring practical knowledge: they need to know that new knowledge is applicable and beneficial.

- Adults want to be treated with respect.

The principles of adult learning theory can be used to plan and guide educational interventions and, more importantly, have been influential on the delivery of educational sessions for healthcare professionals (Fox \& Bennett, 1998; Grol, Wensing, Bosch, Hulscher, \& Eccles, 2013). Specific to this dissertation and in alignment with adult learning theory, the adult learner attending a continuing educational course is motivated 
to learn something that is pertinent to their every-day clinical practice and will be self-directed in their learning style (Merriam et al., 2012). This approach reflects the work of Knowles and the use of andragogy that differs greatly from the more traditional pedagogical approach of entry-level professional, graduate education. Adult learning theory can be applied to action phase 5-monitoring knowledge use within the KTA cycle, because when attending an educational intervention it is not simply about gaining knowledge, but rather about applying the knowledge into daily, clinical practice for the healthcare professional.

Knowledge translation can be best maximized when adult learning theories are used to design educational interventions in health care. The educational intervention should initially assess the learners' needs, existing knowledge, provide clear learning outcomes, and be sure to provide clinically meaningful activities that are relevant to their clinical practice (Collins, 2004; Straus et al., 2013). These activities may include small group discussion, case scenarios, computer-based modules, simulation, and academic outreach visits (Straus et al., 2013).

An adult learner is goal-directed and desires to learn how an educational session will assist them with their personal objectives (Knowles, 1970, 1980). For example, the facilitator of an educational continuing education course fosters adult learning by providing clear objectives at the start of the learning session to set realistic expectations (Collins, 2004; Knowles, 1980). The adult learner is motivated to attack realistic problems when they pertain to practical, everyday situations (Grol et al., 2013). Lastly, the adult learner desires to integrate existing knowledge with new knowledge that can be further facilitated with the proper learning environment. The facilitator or teacher during 
an educational intervention should promote a variety of learning activities that allow for different domains of learning to foster optimal KT to their local clinical environment. These learning activities need to be staged so that they are practical, clinically relevant, and can be easily transferred into clinical practice (Straus et al., 2013). In the midst of an educational activity, although the adult learner will be self-directed, there needs to be coaching and feedback from the teacher or facilitator to foster the integration of new and usable knowledge to further enhance KT in clinical practice (Collins, 2004).

Despite the strong theoretical foundations contained within educational theory, there continues to be limited evidence to support these theories as it relates to the KTA cycle and the fifth action phase of monitoring knowledge use (Stuart et al., 2004). The main reason for the lack of evidence is the difficulty in validating the methodology and practical issues used within the research (Stuart et al., 2004). Understanding these limitations assists researchers to design and measure educational interventions that can test the important theoretical assumptions of an educational theory, such as adult learning theory (Stuart et al., 2004).

There is a growing body of research on understanding of the effectiveness of an educational intervention and its ability to influence the use of knowledge (Gilbody, Whitty, Grimshaw, \& Thomas, 2003; Grimshaw, Eccles, Lavis, Hill, \& Squires, 2012). Research in the area of continuing education has yielded evidence about the type of educational intervention and activities that foster KT (Mazmanian \& Davis, 2002; Stuart et al., 2004). A recent systematic review by Bloom (2005) recommended that educational interventions should not simply be traditional, teacher-led lectures accompanied by handouts. Rather educational sessions should be interactive (Forsetlund et al., 2009), 
involve use of the research evidence by trained professionals in the field of interest (Bloom, 2005; O'Brien et al., 2007), and offer a method of continual communication and support to enhance KT and affect the health care practitioners' behavior. There is evidence to support that assessment of a learner's baseline knowledge, and their learning styles will promote further integration and collaboration for KT throughout the KTA cycle (Straus et al., 2013).

Based on the limited research evidence, it is evident that there is a need for educational research to focus on KT and its supporting theories to improve the clinical practice of physical therapists. Knowledge translation and the KTA cycle provide a strong conceptual framework, supported by theory; however, very little of this framework has been applied to physical therapy. There is a need to understand how new knowledge — for example, after attending a continuing education course — is adapted to the local context or clinical environment—action phase 2. One way to learn how knowledge is adapted to the local clinical environment or context could be to determine a physical therapists' practice style traits and further determining how their traits impact the later action phases. In addition, there is a lack of evidence about action phase 3-barriers to knowledge use and 5-monitoring knowledge use within the KTA cycle in terms of a physical therapists' barriers, facilitators, attitudes, knowledge, behavior, and prerequisites after attending an educational intervention specific to OMs. As stated by Gail Jensen in her 2011 APTA Mary McMillan Lecture:

Although we have accomplished a great deal in enhancing our curricula and establishing and growing our knowledge base in the areas of movement science, motor learning, and motor control theory, we have done far less in incorporating 
and understanding the role of social, cognitive, and social-cultural theories of learning. (Jensen, 2011, p. 1678)

\section{Hypotheses}

Operational null hypothesis: There is no relationship between practice style traits and barriers, facilitators, attitudes, knowledge, behaviors and prerequisites for KT.

Research hypothesis: There is a relationship between practice style traits and barriers, facilitators, attitudes, knowledge, behaviors and prerequisites for KT. 


\section{Chapter 4}

Methodology

\section{Research Design}

This dissertation uses a descriptive research design. A descriptive research design is a study that assists with answering specific questions related to a particular research problem and best describes the status of a phenomena, with respect to variables, in a particular situation or environment (University of Southern California [USC] Libraries, 2015). This research has been approved by the University of St. Augustine's Internal Review Board (IRB) on August 1, 2013 and is identified as \#UR-0819-005.

\section{Study Population}

The study population is physical therapists who have previously attended an evidence-based outcome measures (OMs) continuing education course. Participants are licensed, practicing clinicians who self-selected to attend this particular continuing education course. Participants were identified by email addresses from course registration that was provided by the Neurology Section's administrative support in alignment with IRB \#UR-0819-005. One hundred and thirty-seven past course participants received an email invitation to complete the informed consent, the Practice Style Questionnaire, and the Evidence-based Practice (EBP) Questionnaire.

\section{Data Collection Tools}

Two standardized and validated survey instruments will be used for data collection. They are the Practice Style Questionnaire and the EBP Questionnaire. The Practice Style Questionnaire (Appendix A) is a 17-item questionnaire where subjects are asked a series of questions on a 5-point Likert scale with responses ranging from 
strongly agree to strongly disagree in terms of how they respond to research evidence (Green et al., 2002). The Practice Style Questionnaire has been determined to be a reliable and valid survey instrument with internal consistencies ranging from $0.68-0.79$ as measured by Cronbach's alpha (Green et al., 2002). This survey categorizes a practicing clinician's response to new evidence into one of four categories: seekers, receptives, traditionalists, or pragmatists. The four categories were determined from the interaction of three underlying theoretical factors: (a) extent to which scientific evidence, rather than clinical-experience and authority is perceived as the best source of knowledge about good practice (evidence versus experience), (b) degree of comfort with clinical practices that are out of step with the local community's practices or the recommendations of leaders (nonconformity), (c) importance attached to managing workload and patient flow while maintaining general patient satisfaction (practicality)

(Green et al., 2002).

The second questionnaire used for data collection is the EBP Questionnaire (Appendix B). The EBP Questionnaire is a 31-item questionnaire where subjects are asked a series of questions related to demographics, barriers, facilitators, attitudes, knowledge, behaviors and prerequisites for knowledge in relation to EBP and application of evidence-based guidelines specific to the use of OMs in clinical practice (Bernhardsson \& Larsson, 2013). This survey demonstrates good face and content validity as well as acceptable reliability with agreement ranging from 60-80\% (Bernhardsson \& Larsson, 2013). 


\section{Variables}

\section{Dependent Variable}

The dependent variables are the motivational and cognitive aspects of the physical therapist. These ordinal variables include barriers, facilitators, attitudes, knowledge, behaviors, and prerequisites for knowledge (Bernhardsson and Larsson, 2013). These variables are operationally defined as the clinicians' reasons for selecting evidence-based OMs that are used in daily clinical practice (Bernhardsson \& Larsson, 2013).

\section{Independent Variable}

The independent variables are the physical therapists' practice style traits and personal demographic information including gender, age, number of years in practice, highest degree earned, practice setting, and whether the participant has an American Board of Physical Therapy Specialties certification. The ordinal variables of practice style traits are operationally defined as a practicing clinician's responses in terms of how they respond to new evidence for use in clinical practice.

\section{Statistical Analysis}

Data were collected from both the EBP Questionnaire and the Practice Style from past course participants who previously attended the evidence-based continuing education course specific to OMs. Study data were analyzed using the SPSS statistical package (SPSS, YEAR). Descriptive statistics were used to analyze subject demographic information, individual responses on the EBP questionnaire, and to categorize the responses based on the four question domains: attitudes, knowledge and knowledge prerequisites, behaviors, and barriers/facilitators (Bernhardsson \& Larsson 2013). In addition, descriptive statistics were used to analyze the individual question responses and 
total score on the Practice Style Questionnaire (Green et al., 2002). One-way analysis of variance procedures were used to compare the practice style traits to the four question domains of the EBP Questionnaire. Significance was set at a $p$-value $=0.0125$ based on using the Bonferroni correction. Lastly, post hoc statistics included Tukey and Chi Square analyses, to look at each question in the EBP Questionnaire by practice trait and significance for these post hoc tests, was determined to be a $p$-value $=.05$. Dependent and independent variables are listed in Table 3.

Table 3

Summary of Variables

\begin{tabular}{lc}
\hline Dependent variables & Independent variables \\
\hline Motivational \& Cognitive Constructs & Practice Style Traits \\
for EBP \& knowledge translation (KT) & Seekers \\
of CPGs/OMs & Receptives \\
Behaviors & Traditionalists \\
Facilitators & Pragmatists \\
Attitudes & \\
Knowledge & \\
Behaviors & \\
Prerequisites & \\
& \\
& Demographics \\
& Gender \\
& Age \\
& Number of years in practice \\
& Highest degree earned \\
& Practice setting \\
& APTA Designated Certified Specialist \\
\hline
\end{tabular}




\section{Chapter 5}

Data Analysis and Presentation of Results

\section{Participants}

Completed questionnaires were received from 79 participants, for a response rate of $57 \%$. Eighty-five percent of the participants were female, and $15 \%$ were male. The majority (73\%) were between 30-49 years old and were American Physical Therapy Association (APTA) members (79\%). Of the APTA members, the Neurology Section had the greatest number of participants at $66 \%$. In addition, years in clinical practice was somewhat evenly distributed between 3-20 years, with the smallest percent (4\%) for less than 3 years and the greatest percent $(25 \%)$ reporting $>20$ years of clinical experience. Lastly, $65 \%$ of the participants who were APTA members held specialty certifications and out and in-patient rehabilitation represented the most common area of clinical practice $(66 \%)$ (see Table 4$)$.

\section{Practice Style Questionnaire}

For the 79 participants, the Practice Style Questionnaire was totaled, using reverse scoring for item numbers: $1,5,7,9,15$, and 17 . Reverse scoring was used for these specified items because they were negatively keyed on the questionnaire. The total scores were then compared to the work of Green and colleagues (2002) to determine the participants practice style trait (Table 5). Of the 79 participants, $28 \%$ were seekers, $49 \%$ were pragmatists, and $23 \%$ were receptives. There were no traditionalist participants in the sample (see Table 6). 
Table 4

Demographic Information for 79 Participants

\begin{tabular}{|c|c|c|}
\hline Variable & $N$ & Percent \\
\hline Male/Female & $12 / 67$ & $15 / 85$ \\
\hline \multicolumn{3}{|l|}{ Age group } \\
\hline $20-29$ & 6 & 7 \\
\hline $30-39$ & 36 & 46 \\
\hline $40-49$ & 21 & 27 \\
\hline $50-59$ & 13 & 16 \\
\hline$>60$ & 3 & 4 \\
\hline \multicolumn{3}{|l|}{ Years in clinical practice } \\
\hline$<3$ & 3 & 4 \\
\hline $3-5$ & 10 & 13 \\
\hline $6-10$ & 15 & 19 \\
\hline $11-15$ & 19 & 24 \\
\hline $16-20$ & 12 & 15 \\
\hline$>20$ & 20 & 25 \\
\hline \multicolumn{3}{|l|}{ Highest degree earned } \\
\hline Bachelors & 6 & 7 \\
\hline Masters & 19 & 24 \\
\hline DPT & 26 & 33 \\
\hline t-DPT & 21 & 27 \\
\hline Terminal Doctorate & 7 & 9 \\
\hline \multicolumn{3}{|l|}{ APTA Member } \\
\hline Yes/No & $62 / 17$ & $79 / 21$ \\
\hline \multicolumn{3}{|l|}{$\begin{array}{l}\text { If APTA Section Member, which } \\
\text { section? }\end{array}$} \\
\hline Acute Care & 9 & 11 \\
\hline Aquatics & 1 & 1 \\
\hline Cardiopulmonary & 1 & 1 \\
\hline Education & 9 & 11 \\
\hline Geriatrics & 9 & 11 \\
\hline Hand Rehabilitation & 1 & 1 \\
\hline Health Policy \& Administration & 1 & 1 \\
\hline Home Health & 3 & 4 \\
\hline Neurology & 52 & 66 \\
\hline Oncology & 2 & 3 \\
\hline Orthopedics & 3 & 4 \\
\hline Pediatrics & 3 & 4 \\
\hline Research & 4 & 5 \\
\hline Sports & 1 & 1 \\
\hline
\end{tabular}


Table 4 (continued)

\begin{tabular}{|c|c|c|}
\hline Variable & $N$ & Percent \\
\hline \multicolumn{3}{|l|}{ ABPTS certification } \\
\hline Yes/No & $44 / 35$ & $56 / 44$ \\
\hline \multicolumn{3}{|l|}{ Primary place of employment } \\
\hline Acute Care & 10 & 13 \\
\hline Academic & 9 & 12 \\
\hline Home Health & 2 & 3 \\
\hline Inpatient Rehabilitation & 24 & 30 \\
\hline Outpatient Rehabilitation & 20 & 36 \\
\hline Research & 1 & 1 \\
\hline Skilled Nursing & 4 & 5 \\
\hline \multicolumn{3}{|l|}{$\begin{array}{l}\text { Number of physical therapists at } \\
\text { main place of employment }\end{array}$} \\
\hline$<3$ & 4 & 5 \\
\hline $3-5$ & 13 & 16 \\
\hline $6-10$ & 17 & 21 \\
\hline $11-15$ & 15 & 19 \\
\hline$>15$ & 30 & 39 \\
\hline \multicolumn{3}{|l|}{$\begin{array}{l}\text { Portion of total work spent with } \\
\text { patient care }\end{array}$} \\
\hline$<25 \%$ & 10 & 13 \\
\hline $26-50 \%$ & 9 & 12 \\
\hline $51-75 \%$ & 16 & 20 \\
\hline$>75 \%$ & 44 & 54 \\
\hline
\end{tabular}

Table 5

Practice Style Questionnaire-Scale Scores to Determine Practice Style Trait

\begin{tabular}{llll}
\hline Practice style trait & \multicolumn{1}{c}{$\begin{array}{c}\text { Evidence vs. experience } \\
\text { (range, 6-30) }\end{array}$} & $\begin{array}{c}\text { Nonconformity } \\
\text { (range, 6-30) }\end{array}$ & \multicolumn{1}{c}{$\begin{array}{c}\text { Practicality } \\
\text { (range, 5-25) }\end{array}$} \\
\hline Seeker & Extreme evidence end: $\geq 22$ & High: $>18$ & Not high: $\leq 14$ \\
Receptive & Toward evidence end: $\geq 18$ & Moderate: $\leq 18$ & Not high: $\leq 14$ \\
Traditionalist & Toward experience end: $<18$ & Variable & Not high: $\leq 14$ \\
Pragmatist & Variable & Variable & High: $>14$ \\
\hline
\end{tabular}

Note. Adapted from "Validating an Instrument for Selecting Interventions to Change Physician Practice Patterns," by L. A. Green, D. W. Gorenflo, and L. Wyszewianski, 2002, Journal of Family Practice, 51(11), p. 942. 
Table 6

Practice Style Questionnaire-Total Scores to Determine Practice Style Trait

\begin{tabular}{lcc}
\hline Practice style trait & $N$ & Percent \\
\hline Seeker & 22 & 28 \\
Receptive & 18 & 23 \\
Traditionalist & 0 & 0 \\
Pragmatist & 39 & 49 \\
\hline
\end{tabular}

Note. There were no Traditional group members in the sample.

\section{Evidence-Based Practice Questionnaire Domains and Their Relevance to Evidence-Based Practice and Guidelines/Outcome Measures}

For the 79 participants, the Evidence-based Practice (EBP) Questionnaire responses were looked at by individual questions for sections $\mathrm{B}$ and $\mathrm{C}$ (questions 9-32). Question 32 was an additional qualitative question. It is important to note that questions 9-31 are grouped by domain. The four domains are as listed below.

- Attitude Domain-Questions 9-13, 18-21, 27-29

- Knowledge Domain-Questions 16, 22, 23, 26

- Behavior Domain-Questions 14, 15, 25

- Barriers and Prerequisites Domain-Questions 17, 24, 30, 31

\section{Evidence-Based Practice Questionnaire-Individual Questions}

\section{for Sections B and C (Questions 9-32)}

Following are the results of Sections B and C of the Evidence-Based Questionnaire. 
Section B: Questions about attitudes toward, use of, and perceived benefits and limitations of evidence-based practice. Results of Questions 9-17 are shown in Tables 7-17.

Table 7

Question 9 (Attitude Domain) - I Consider It Necessary to Apply EBP in the Daily Practice of Physical Therapy

\begin{tabular}{lcc}
\hline Response & $N$ & Percent \\
\hline Strongly disagree & 2 & 3 \\
Neutral & 2 & 3 \\
Agree & 53 & 66 \\
Strongly agree & 22 & 28 \\
\hline
\end{tabular}

Table 8

Question 10 (Attitude Domain) —I Think it Creates Unreasonable Demands to Apply EBP in My Daily Work

\begin{tabular}{lcc}
\hline Response & $N$ & Percent \\
\hline Strongly disagree & 21 & 26 \\
Disagree & 47 & 60 \\
Neutral & 9 & 12 \\
Agree & 1 & 1 \\
Strongly agree & 1 & 1 \\
\hline
\end{tabular}


Table 9

Question 11 (Attitude Domain) - I Want to Learn and Improve the Knowledge and Skills Necessary to Apply EBP in My Work

\begin{tabular}{lcc}
\hline Response & $N$ & Percent \\
\hline Strongly disagree & 1 & 1 \\
Neutral & 1 & 1 \\
Agree & 35 & 44 \\
Strongly agree & 42 & 54 \\
\hline
\end{tabular}

Table 10

Question 12 (Attitude Domain)—Strong Evidence Is Lacking for Most Treatments That I Use for My Patients

\begin{tabular}{lcc}
\hline Response & $N$ & Percent \\
\hline Strongly disagree & 3 & 4 \\
Disagree & 28 & 35 \\
Neutral & 15 & 19 \\
Agree & 26 & 33 \\
Strongly agree & 7 & 9 \\
\hline
\end{tabular}

Table 11

Question 13 (Attitude Domain)_EBP Can Help Me Make Decisions in the Choice of Treatment

\begin{tabular}{lcc}
\hline Response & $N$ & Percent \\
\hline Strongly disagree & 1 & 1 \\
Neutral & 3 & 4 \\
Agree & 50 & 64 \\
Strongly agree & 25 & 31 \\
\hline
\end{tabular}


Table 12

Question 14 (Behavior Domain)—Number of Scientific Articles Related to My Clinical Work That I Read During a Typical Month

\begin{tabular}{lcc}
\hline Response & $N$ & Percent \\
\hline 1 & 16 & 20 \\
$2-5$ & 37 & 46 \\
$6-10$ & 21 & 27 \\
$11-15$ & 3 & 4 \\
$16+$ & 2 & 3 \\
\hline
\end{tabular}

Table 13

Question 15 (Behavior Domain)_Number of Times I Use PubMed or Other Databases to Search Literature That Is Relevant to My Clinical Work During a Typical Month

\begin{tabular}{lcc}
\hline Response & $N$ & Percent \\
\hline 1 & 24 & 30 \\
$2-5$ & 25 & 32 \\
$6-10$ & 17 & 22 \\
$11-15$ & 8 & 10 \\
$16+$ & 5 & 6 \\
\hline
\end{tabular}

Table 14

Question 16 (Knowledge Domain)_I Know How to Access Relevant Databases

\begin{tabular}{lcc}
\hline Response & $N$ & Percent \\
\hline Strongly disagree & 1 & 1 \\
Disagree & 4 & 5 \\
Neutral & 6 & 7 \\
Agree & 36 & 47 \\
Strongly agree & 32 & 40 \\
\hline
\end{tabular}


Table 15

Question 17 (Barriers and Prerequisites)—At My Place of Work the Use of Current Research Is Encouraged

\begin{tabular}{lcc}
\hline Response & $N$ & Percent \\
\hline Strongly disagree & 7 & 8 \\
Disagree & 6 & 7 \\
Neutral & 8 & 10 \\
Agree & 26 & 33 \\
Strongly agree & 32 & 42 \\
\hline
\end{tabular}

Table 16

Question 18 (Attitude Domain)_I Feel Confident in My Ability to Find Relevant Research to Answer My Clinical Questions

\begin{tabular}{lcc}
\hline Response & $N$ & Percent \\
\hline Strongly disagree & 1 & 1 \\
Disagree & 6 & 7 \\
Neutral & 11 & 14 \\
Agree & 36 & 46 \\
Strongly agree & 25 & 32 \\
\hline
\end{tabular}

Table 17

Question 19 (Attitude Domain)_I Feel Confident in My Ability to Treat My Patients According to Current Evidence

\begin{tabular}{lcc}
\hline Response & $N$ & Percent \\
\hline Strongly disagree & 1 & 1 \\
Disagree & 1 & 1 \\
Neutral & 10 & 12 \\
Agree & 49 & 63 \\
Strongly agree & 18 & 23 \\
\hline
\end{tabular}




\section{Section C: Questions about attitudes toward and use of clinical practice}

guidelines/outcome measures. Results of Questions 20-30 are shown in Tables 18-28.

Table 18

Question 20 (Attitude Domain) - I Consider It Important That Easily Available Evidence-based Guidelines/Outcome Measures Related to My Work Exist

\begin{tabular}{lcc}
\hline Response & $N$ & Percent \\
\hline Strongly disagree & 1 & 1 \\
Disagree & 2 & 3 \\
Neutral & 4 & 5 \\
Agree & 30 & 38 \\
Strongly agree & 42 & 53 \\
\hline
\end{tabular}

Table 19

Question 21 (Attitude Domain)—I Consider It Important to Use Evidence-based Guidelines/Outcome Measures in My Work

\begin{tabular}{lcc}
\hline Response & $N$ & Percent \\
\hline Strongly disagree & 1 & 1 \\
Neutral & 2 & 3 \\
Agree & 32 & 40 \\
Strongly agree & 44 & 56 \\
\hline
\end{tabular}

Table 20

Question 22 (Knowledge Domain)_I'm Aware That Evidence-based Guidelines/Outcome Measures for Diagnoses Relevant to My Work Exist

\begin{tabular}{lcc}
\hline Response & $N$ & Percent \\
\hline Yes & 63 & 79 \\
Partially & 14 & 18 \\
No & 2 & 3 \\
\hline
\end{tabular}


Table 21

Question 23 (Knowledge Domain) -I Know How and Where to Find Evidence-based Guidelines/Outcome Measures Related to My Work on the Internet

\begin{tabular}{lcc}
\hline Response & $N$ & Percent \\
\hline Yes & 58 & 73 \\
Partially & 21 & 27 \\
\hline
\end{tabular}

Table 22

Question 24 (Barriers and Prerequisites)_I Have Fast and Easy Access to Relevant Evidence-based Guidelines/Outcome Measures at My Place of Work

\begin{tabular}{lcc}
\hline Response & $N$ & Percent \\
\hline Strongly disagree & 3 & 4 \\
Disagree & 13 & 16 \\
Neutral & 11 & 14 \\
Agree & 27 & 34 \\
Strongly agree & 25 & 32 \\
\hline
\end{tabular}

Table 23

Question 25 (Behavior Domain)—I Use Evidence-based Guidelines/Outcome Measures in My Work

\begin{tabular}{lcc}
\hline Response & $N$ & Percent \\
\hline Strongly disagree & 1 & 1 \\
Neutral & 24 & 30 \\
Agree & 23 & 29 \\
Strongly agree & 31 & 40 \\
\hline
\end{tabular}


Table 24

Question 26 (Knowledge Domain) -I Can Integrate the Patients' Preferences With Evidence-based Guidelines/Outcome Measures

\begin{tabular}{lcc}
\hline Response & $N$ & Percent \\
\hline Strongly disagree & 2 & 3 \\
Neutral & 14 & 18 \\
Agree & 40 & 50 \\
Strongly agree & 23 & 29 \\
\hline
\end{tabular}

Table 25

Question 27 (Attitude Domain)_Evidence-based Guidelines/Outcome Measures Are Important to Facilitate My Work

\begin{tabular}{lcc}
\hline Response & $N$ & Percent \\
\hline Strongly disagree & 1 & 1 \\
Disagree & 1 & 1 \\
Neutral & 10 & 12 \\
Agree & 41 & 52 \\
Strongly agree & 26 & 34 \\
\hline
\end{tabular}

Table 26

Question 28 (Attitude Domain)_Evidence-based Guidelines/Outcome Measures Are Important so That the Patients Receive the Best Possible Treatment

\begin{tabular}{lcc}
\hline Response & $N$ & Percent \\
\hline Strongly disagree & 1 & 1 \\
Disagree & 2 & 3 \\
Neutral & 3 & 4 \\
Agree & 47 & 60 \\
Strongly agree & 26 & 32 \\
\hline
\end{tabular}


Table 27

Question 29 (Attitude Domain)_Evidence-based Guidelines/Outcome Measures Are Important so That the Patients Receive Equal Treatment

\begin{tabular}{lcc}
\hline Response & $N$ & Percent \\
\hline Strongly disagree & 1 & 1 \\
Neutral & 19 & 24 \\
Agree & 45 & 57 \\
Strongly agree & 14 & 18 \\
\hline
\end{tabular}

Table 28

Question 30 (Barriers and Prerequisites)_Factors below That Constitute the Greatest Barriers to Using Evidence-based Guidelines/Outcome Measures

\begin{tabular}{lcc}
\hline Response & $N$ & Percent \\
\hline Lack of time & 57 & 72 \\
No guidelines & 27 & 34 \\
Cannot find guidelines & 14 & 18 \\
Too long to read guidelines & 22 & 28 \\
Guidelines too general & 25 & 32 \\
Guidelines too specific & 10 & 13 \\
Lack of support & 10 & 13 \\
Lack of interest & 1 & 1 \\
\hline
\end{tabular}

Question 31 was a qualitative/open-ended question asking which diagnoses would you benefit the most from having evidence-based guidelines/outcome measures.

Participants were asked to state up to five diagnoses. Responses included: stroke (60), traumatic brain injury (42), Parkinson's disease (33), multiple sclerosis (29), and spinal cord injury (23). Other responses included: vestibular (14), falls/balance/ataxia (10), peripheral neuropathy/Guillain-Barre syndrome (9), amputee (7), and concussion (6). 
Question 32 was a qualitative/open-ended question asking the participants the five most frequently used outcome measures (OMs) used in their clinical practice. Responses included: Berg balance test (42), Timed Up and Go (35), 10-meter walk test/gait velocity (27), 6-minute walk test (30), and Functional Gait Assessment (22). Other responses included: Dynamic Gait Index (18), 5 times sit-to-stand (14), Functional Independence Measure (10), Dizziness Handicap Inventory (6), Activities Specific Balance Confidence Scale (6), and Tinetti Performance Oriented Mobility Assessment (6).

\section{Combination of Both the Practice Style and}

\section{Evidence-Based Practice Questionnaires}

For the 79 participants, the Practice Style Traits were then combined with the four domains of the EBP Questionnaire using statistics to analyze the amount of variance between the groups. These findings pertain to Tables 29 and 30 .

Table 29

ANOVA-Practice Style Trait With Four Domains of Evidence-based Practice Questionnaire

\begin{tabular}{lc}
\hline Four domains & Significance \\
\hline Attitude & .018 \\
Knowledge & .025 \\
Behavior* & .000 \\
Barriers and prerequisites & .030 \\
\hline
\end{tabular}

*Behavior is the only domain where there are significant differences among groups. 
Table 30

Test for Homogeneity of Variance

\begin{tabular}{lcc}
\hline Four domains & Levene statistic & Significance \\
\hline Attitude & .265 & .768 \\
Knowledge & 1.764 & .178 \\
Behavior & .113 & .893 \\
Barriers and prerequisites & 2.427 & .095 \\
\hline
\end{tabular}

Note. There is homogeneity of variance for all four domains; there is no statistical significance.

\section{Post Hoc Analyses}

\section{Tukey HSD}

For behavior, seekers are significantly different from both the pragmatists and receptives; however, the pragmatists and receptives are not significantly different from each other.

\section{Chi Square Analyses: Evidence-based Practice Questionnaire}

\section{by Practice Style Trait}

ONLY questions that were statistically significant were reported. These results are displayed in Tables 31-38.

Table 31

Question 15 (Behavior Domain)_Number of Times I Use PubMed or Other Databases to Search Literature That Is Relevant to My Clinical Work During a Typical Month

\begin{tabular}{lcccccc}
\hline Practice style traits & 1 & $2-5$ & $6-10$ & $11-16$ & $16+$ & Total \\
\hline Seeker & 2 & 5 & 8 & 5 & 2 & 22 \\
Receptive & 7 & 4 & 3 & 1 & 0 & 18 \\
Pragmatist & 15 & 16 & 3 & 2 & 3 & 39 \\
\hline
\end{tabular}

Note. Pearson Chi-Square $=.013 /$ significant difference between practice style traits. 
Table 32

Question 16 (Knowledge Domain)—I Know How to Access Relevant Databases

\begin{tabular}{lcccccc}
\hline & $\begin{array}{c}\text { Strongly } \\
\text { disagree }\end{array}$ & Disagree & Neutral & Agree & $\begin{array}{c}\text { Strongly } \\
\text { agree }\end{array}$ & Total \\
\hline Seeker & 0 & 2 & 0 & 4 & 16 & 22 \\
Receptive & 0 & 0 & 3 & 9 & 6 & 18 \\
Pragmatist & 1 & 2 & 2 & 24 & 10 & 39 \\
\hline
\end{tabular}

Note. Pearson Chi-Square $=.005 /$ significant difference between practice style traits.

Table 33

Question 17 (Barriers and Prerequisite Domain)_At My Place of Work the Use of Current Research is Encouraged

\begin{tabular}{lcccccc}
\hline & $\begin{array}{c}\text { Strongly } \\
\text { disagree }\end{array}$ & Disagree & Neutral & Agree & $\begin{array}{c}\text { Strongly } \\
\text { agree }\end{array}$ & Total \\
\hline Seeker & 0 & 1 & 0 & 4 & 16 & 22 \\
Receptive & 0 & 1 & 0 & 10 & 7 & 18 \\
Pragmatist & 5 & 3 & 8 & 12 & 11 & 39 \\
\hline
\end{tabular}

Note. Pearson Chi-Square $=.003 /$ significant difference between practice style traits.

Table 34

Question 19 (Attitude Domain)_I Feel Confident in My Ability to Treat Patients According to Current Evidence

\begin{tabular}{lcccccc}
\hline & $\begin{array}{c}\text { Strongly } \\
\text { disagree }\end{array}$ & Disagree & Neutral & Agree & $\begin{array}{c}\text { Strongly } \\
\text { agree }\end{array}$ & Total \\
\hline Seeker & 0 & 0 & 1 & 10 & 11 & 22 \\
Receptive & 0 & 1 & 1 & 15 & 2 & 18 \\
Pragmatist & 1 & 0 & 7 & 25 & 5 & 39 \\
\hline
\end{tabular}

Note. Pearson Chi-Square $=.029 /$ significant difference between practice style traits. 
Table 35

Question 21 (Attitude Domain)_I Consider It Important to Use Evidence-Based Guidelines/Outcome Measures in My Work

\begin{tabular}{lccccc}
\hline & $\begin{array}{c}\text { Strongly } \\
\text { disagree }\end{array}$ & Neutral & Agree & $\begin{array}{c}\text { Strongly } \\
\text { agree }\end{array}$ & Total \\
\hline Seeker & 0 & 0 & 4 & 18 & 22 \\
Receptive & 0 & 1 & 4 & 12 & 18 \\
Pragmatist & 1 & 1 & 23 & 14 & 39 \\
\hline
\end{tabular}

Note. Pearson Chi-Square $=.011 /$ significant difference between practice style traits.

Table 36

Question 25 (Behavior Domain) —I Use Evidence-Based Guidelines/Outcome Measures in My Work

\begin{tabular}{lccccc}
\hline & $\begin{array}{c}\text { Strongly } \\
\text { disagree }\end{array}$ & Neutral & Agree & $\begin{array}{c}\text { Strongly } \\
\text { agree }\end{array}$ & Total \\
\hline Seeker & 0 & 2 & 5 & 15 & 22 \\
Receptive & 0 & 4 & 5 & 8 & 18 \\
Pragmatist & 1 & 18 & 12 & 8 & 39 \\
\hline
\end{tabular}

Note. Pearson Chi-Square $=.016 /$ significant difference between practice style traits.

Table 37

Question 26 (Knowledge Domain) - I Can Integrate the Patients' Preferences With Evidence-Based Guidelines/Outcome Measures

\begin{tabular}{lccccc}
\hline Practice style traits & $\begin{array}{c}\text { Strongly } \\
\text { disagree }\end{array}$ & Neutral & Agree & $\begin{array}{c}\text { Strongly } \\
\text { agree }\end{array}$ & Total \\
\hline Seeker & 1 & 1 & 8 & 12 & 22 \\
Receptive & 0 & 1 & 10 & 6 & 18 \\
Pragmatist & 1 & 12 & 22 & 4 & 39 \\
\hline
\end{tabular}

Note. Pearson Chi-Square $=.004 /$ significant difference between practice style traits. 
Table 38

Question 27 (Attitude Domain)_Evidence-Based Guidelines/Outcome Measures Are Important to Facilitate My Work

\begin{tabular}{lcccccc}
\hline & $\begin{array}{c}\text { Strongly } \\
\text { disagree }\end{array}$ & Disagree & Neutral & Agree & $\begin{array}{c}\text { Strongly } \\
\text { agree }\end{array}$ & Total \\
\hline Seeker & 0 & 0 & 1 & 7 & 14 & 22 \\
Receptive & 0 & 0 & 2 & 9 & 6 & 18 \\
Pragmatist & 1 & 1 & 6 & 25 & 6 & 39 \\
\hline
\end{tabular}

Note. Pearson Chi-Square $=.048 /$ significant difference between practice style traits.

\section{Chi Square Analyses: Demographics}

Only significant categories were reported. These results are displayed in

Tables 39-43.

Table 39

Age Group

\begin{tabular}{lcccccc}
\hline Practice style traits & $20-29$ & $30-39$ & $40-49$ & $50-59$ & $>60$ & Total \\
\hline Seeker & 2 & 6 & 6 & 5 & 3 & 22 \\
Receptive & 1 & 6 & 8 & 3 & 0 & 18 \\
Pragmatist & 3 & 24 & 7 & 5 & 0 & 39 \\
\hline
\end{tabular}

Note. Pearson Chi-Square $=.029 /$ significant difference between practice style traits.

Table 40

Highest Degree Earned

\begin{tabular}{lcccccc}
\hline & & & & \multicolumn{3}{c}{ Terminal } \\
Practice style traits & Bachelors & Masters & DPT & t-DPT & doc & Total \\
\hline Seeker & 1 & 5 & 4 & 6 & 6 & 22 \\
Receptive & 2 & 7 & 6 & 2 & 1 & 18 \\
Pragmatist & 3 & 7 & 16 & 13 & 0 & 39 \\
\hline
\end{tabular}

Note. Pearson Chi-Square $=.007 /$ significant difference between practice style traits. 
Table 41

APTA Member

\begin{tabular}{lccc}
\hline Practice style traits & Yes & No & Total \\
\hline Seeker & 21 & 1 & 22 \\
Receptive & 15 & 3 & 18 \\
Pragmatist & 26 & 13 & 39 \\
\hline Note. Pearson Chi-Square $=.043 /$ significant difference between practice style
\end{tabular}

Note. Pearson Chi-Square $=.043 /$ significant difference between practice style traits.

Table 42

Primary Place of Employment

\begin{tabular}{|c|c|c|c|c|c|c|c|c|}
\hline Practice style traits & Acute & Academic & $\begin{array}{l}\text { Home } \\
\text { health }\end{array}$ & $\begin{array}{l}\text { Inpt. } \\
\text { rehab. }\end{array}$ & $\begin{array}{l}\text { Outpt. } \\
\text { rehab. }\end{array}$ & Research & $\begin{array}{l}\text { Skilled } \\
\text { nursing }\end{array}$ & Total \\
\hline Seeker & 1 & 7 & 0 & 5 & 8 & 1 & 0 & 22 \\
\hline Receptive & 1 & 0 & 1 & 9 & 6 & 0 & 1 & 39 \\
\hline Pragmatist & 8 & 2 & 1 & 10 & 15 & 0 & 3 & 18 \\
\hline
\end{tabular}

Note. Pearson Chi-Square $=.014 /$ significant difference between practice style traits.

Table 43

Portion of Total Time Spent in Patient Care

\begin{tabular}{lccccc}
\hline Practice style traits & $<25 \%$ & $26-50 \%$ & $51-75 \%$ & $>75 \%$ & Total \\
\hline Seeker & 8 & 2 & 4 & 8 & 22 \\
OReceptive & 0 & 1 & 5 & 12 & 18 \\
Pragmatist & 2 & 6 & 7 & 24 & 39 \\
\hline
\end{tabular}

Note. Pearson Chi-Square $=.006 /$ significant difference between practice style traits. 


\section{Chapter 6}

Discussion, Implications of Research, and Conclusions

\section{Discussion}

\section{Practice Style Traits}

This study was interested in learning about who made up the local, clinical context (action phase 2 in the Knowledge to Action [KTA] cycle) by determining practice style traits of physical therapists after attending an evidence-based course specific to the use of outcome measures (OMs). For this group of participants, 28\% were seekers, $49 \%$ were pragmatists, and $23 \%$ were receptives. It should be noted that there were no traditionalists found in this group. In addition, these subjects represent a significant percentage of seekers.

The Practice Style Questionnaire was validated on physicians and determined that the survey was based on the three theoretical principles of evidence versus experience, degree of nonconformity, and amount of practicality (Green et al., 2002). Physicians could then be categorized into one of the four practice style traits of a seeker, receptive, traditionalist, or pragmatist (Green et al., 2002). When surveying physicians, Green and colleagues (2002) reported the seeker to be the rarest practice style trait at $2.5 \%$, followed by the traditionalists at $12.6 \%$, pragmatists at $27.9 \%$, and finally $57 \%$ for receptives. Similar findings were reported when this survey tool was used with physical and occupational therapists practicing in stroke rehabilitation across Canada. KornerBitensky, Menon-Nair, Thomas, Boutin, and Arafah (2008) had the greatest number of pragmatists at 55\% and fewest number of seekers 6\%. Lastly, when the Practice Style Questionnaire was used with student physical and occupational therapists in Canada, the 
most prevalent trait was pragmatists at $53 \%$ and the least common trait was the seeker at $<1 \%$ (Hadouda et al., 2009). Past research has physicians, physical and occupational therapists, and physical and occupational therapy students reporting the greatest percentage of pragmatists and fewest percentage of seekers.

Comparing this study with prior research studies, has yielded different results. This study found the greatest percentage of pragmatists (49\%), like the two Canadian studies on therapists and therapy students, but this is unlike the physicians who reported the greatest percentage of receptives (57\%). It appears that physical therapists have a higher percentage of variability in their clinical decision-making when weighing the use of evidence versus experience, as seen by the range of practice style traits. In addition, the greatest percentage of pragmatists might define who physical therapists are as a profession, as pragmatists have a variable degree of nonconformity with the local, clinical environment, and clinical decision-making is based on practicality when managing their workload. Research evidence in the local, clinical environment needs to be readily available and efficiently accessed in order for knowledge translation (KT) to occur (Grimshaw, Eccles, Walker, \& Thomas, 2002). The other significant difference between this study and prior research is the greater percentage of seekers reported. This could be explained by the fact that this study's participants self-selected to attend the evidencebased course specific to the use of OMs and that these subjects would be more evidence-seeking as compared to subjects in past studies. The greater percentage of seekers does, in fact, highlight the participants as a whole, and ideally these subjects have the greatest potential for KT when returning to their local, clinical environments (Green et al., 2002; Green et al., 2007). Seekers rely most heavily on evidence to make their 
clinical decisions and tend not to conform to the local, clinical environment. These strengths can be viewed and incorporated into future continuing education courses and by offering ongoing, active support (Grimshaw et al., 2001; Grimshaw et al., 2002;

Grimshaw et al., 2012). Examples of ongoing, active engagement in the local, clinical environment that are supported by social cognitive and educational theories include the use of chart audits, email reminders, or pop-ups connected to the electronic medical record, and the use of applications on tablets and personal computers to a targeted audience. Knowledge of the practice style traits assists in targeting the dissemination plans for optimal KT of Evidence-based Clinical Practice Guidelines (EBCPGs) and OMs into clinical practice.

\section{Evidence-Based Practice Questionnaire}

This study was also interested in determining barriers to knowledge use (action phase 3) and monitoring knowledge use (action phase 5) within the KTA cycle. This was accomplished through the use of the Evidence-based Practice (EBP) Questionnaire. The EBP Questionnaire has been validated to determine the attitudes, knowledge, behavior, barriers, and prerequisites related to EBP and guidelines. Although this questionnaire had 32 items and included the demographic data, the questions are grouped into four domains: attitude toward EBP and guidelines, knowledge about EBP resources and guidelines, behavior related to EBP and guidelines, and barriers and prerequisites for knowledge use (see Appendix B).

The attitude domain contains 12 questions, which are supported by both action phases 3 and 5 of barriers and prerequisites and monitoring knowledge use within the KTA cycle. Of the subjects surveyed, $94 \%$ believed it was necessary to apply EBP within 
the daily practice of physical therapy, and $86 \%$ of the subjects reported that using EBP did not create unreasonable demands in the clinical environment. Also, interesting to note that despite the strong beliefs regarding the use of EBP, $98 \%$ would choose to learn and improve their knowledge and skills in applying EBP to their work. This $98 \%$ represents a significant opportunity for future research aimed at eager participants who desire to improve and apply EBP to the local, clinical environment and thus further KT strategies. To meet the needs and foster the opportunities to improve their knowledge and skills in applying EBP to their work, further coursework and on-going support for EBCPGs and OMs could be implemented. Also, within the attitude domain questions $95 \%$ of the subjects reported that EBP helps in the decision-making process for treatments, although $42 \%$ reported that strong evidence for most treatments was lacking. Further, greater than $78 \%$ of the subjects felt confident in their ability to find relevant research to answer clinical questions and to treat their patients according to current evidence. Ninety-one percent of subjects agreed that EBCPGs and OMs were readily available in their clinical environment, and greater than $86 \%$ considered it important to use EBCPGs and OMs to facilitate their work. Lastly, 92\% of subjects reported that EBCPGs and OMs were important so that the patient received the best possible treatment, and $75 \%$ reported that the use also allowed patients to receive equal treatment. The attitude domain responses from the EBP Questionnaire certainly support a stronger viewpoint for the importance of EBP in terms of desirability for its use to access and assist in clinical-decision making; however, a gap remains in both knowledge and application of this knowledge in clinical practice. Future efforts need to be directed at the delivery and support for EBCPGs and 
OMs so the uptake and usability continue to promote evidence-based clinical decisionmaking that will optimize patient outcomes.

The knowledge domain of the EBP Questionnaire involved four questions, which can be reflected in both action phases 3 and 5 within the KTA cycle. Eighty-seven percent of the subjects reported that they knew how to access relevant databases; however, 21\% were not aware that EBCPGs and OMs existed for diagnoses relevant to their area of clinical practice. In addition, only $73 \%$ were knowledgeable about how and where to locate EBCPGs and OMs on the internet. Lastly, it is significant to note that $79 \%$ of those that are using EBCPGs and OMs are able to integrate the use of this evidence into their patients preferences and goals. These results again support an opportunity to increase the level of knowledge and further KT specific to use of EBCPGs and OMs. This support can occur with on-going continuing education courses offered in a variety of delivery formats; however, it can also be driven by increasing requirements to use EBCPGs and OMs by third-party payers driving reimbursement in the healthcare system.

The behavior domain of the EBP Questionnaire involved three questions, which are also supported with both action phases 3 and 5 of the KTA cycle. It is interesting to note that the highest percentage of subjects $(46 \%)$ responded that they read two to five articles per month, and $62 \%$ responded that they searched a database to locate evidence between 1-5 times per month. The above behaviors are in agreement with the $69 \%$ of subjects that reported that they use EBCPGs and OMs in their work. This percentage of EBCPG and OM use is much more significant than prior published studies. It appears that the education efforts and KT have been fruitful over the past 6 years, as Jette and 
colleagues (2009) reported only $48 \%$ of survey respondents using OMs in daily practice. This study is reporting a significantly higher percentage of EBCPG and OM use, perhaps because these participants attended a continuing education course specific to the use and KT of OMs. The reported subject percentages of reading and searching the evidence may not, however, agree with $30 \%$ of the subjects reporting that they are neutral when it comes to actual use of EBCPGs and OMs in daily practice. The behavior domain questions represent the abilities of the physical therapist to locate the evidence; however, a gap remains with the actual implementation of the knowledge related to EBCPGs and OMs.

In looking at individual questions within the four domains, the barriers and prerequisites for knowledge use of EBCPGs and OMs, as defined in action phase 3 of the KTA cycle, yielded similar findings to prior research. The top five reasons selected as the greatest barriers to using EBCPGs/OMs were reported as $72 \%$ —lack of time, $34 \%$ no guidelines/OMs available, $32 \%$ — guidelines/OMs being too general, and 28\%guidelines/OMs being too long. Undoubtedly, lack of time is reported as the greatest barrier to guideline/OM use in clinical practice, and these findings are consistent with other studies (Grimshaw et al., 2002; Grimshaw et al., 2012; D. U. Jette et al., 2009). Interesting to note that, although there are similar barriers published in prior studies, $75 \%$ of subjects in this current study reported that their employers encouraged the use of current research, and $66 \%$ reported that they had fast and easy access to relevant EBCPGs and OMs. These percentages may not be in total agreement with the top five greatest barriers responses. In addition, when asked about which diagnoses they would benefit from having EBCPGs and OMs available (action phase 3 prerequisites for knowledge 
use), the top five neurologic rehabilitation diagnoses emerged. Lastly, when asked to report the top five OMs used in clinical practice, all measures reported are supported with a significant wealth of evidence-based psychometrics across a wide variety of patient populations (APTA, Neurology Section, 2015a; Rehabilitation Measures Database, 2015). Clinically, it is important to identify barriers and prerequisites to knowledge use for maximal $\mathrm{KT}$, and these findings can further impact later action phases within the KTA cycle. Examples of how to minimize these barriers and prime the physical therapists for continual KT with regards to EBCPGs and OMs would be to perform ongoing chart audits, assess reimbursement of physical therapy services, and to develop teams and centers of excellence that can support the daily, clinical environment.

\section{Combination of Practice Style Traits and Evidence-Based Practice Questionnaire}

When the findings of the three practice style traits were combined with the four domains of the EBP Questionnaire, the probability level was conservatively set at .0125 using the Bonferroni correction. Using this probability level, only the behavior domain of the EBP Questionnaire yielded significant differences between the practice style traits. The behavior domain questions in the EBP Questionnaire included the number of scientific articles and database searches related to clinical practice in a typical month and the actual use of EBCPGs and OMs. For the behavior domain questions, seekers were found to be significantly different from both the pragmatists and receptives. Seekers had the highest percentage of database searches, articles read, and report of EBCPG and OM use in clinical practice. The pragmatists and receptives, however, were not significantly different from each other. 
Beyond the behavior domain of questions, there were significant differences between the practice style traits and individual questions of the EBP Questionnaire. These questions included two from the knowledge domain, one from the barrier and prerequisites domain, and three from the attitude domain. The analysis of the responses with the knowledge domain questions concluded that seekers had the greatest know-how to search relevant databases, and seekers were also found to be most agreeable that they could integrate patient preferences with EBCPGs and OMs. On the barriers and prerequisites question related to the use of current research in clinical practice, the seekers and receptives responded similarly with their agreement that the use of current evidence was encouraged in their place of work. The pragmatists, however, were the most varied in their responses, ranging from strongly disagree to strongly agree, as far as the encouragement to use current evidence in their place of work. Analysis of the attitude domain questions indicated that the seekers were the most confident in their abilities and considered it important to treat patients using EBCPG and OMs in order to facilitate their work. Also, to be expected, pragmatists searched evidence-based databases the least number of times during a typical month and had the greatest number of respondents in the 30- to 39-year-old age group. The pragmatists also had the greatest percentage of participants who likely received EBP within their doctorate and transitional doctorates in physical therapy, yet appear to be the least likely to be users of the evidence related to KT of EBCPGs and OMs. These numbers may resemble a stereotype within this age group, and future research should focus more specifically on KT strategies to reach this millennial generation. The seekers collectively had the highest level of education and were APTA members, and the pragmatists and receptives reported spending $>75 \%$ of 
their work time in direct patient care. Perhaps the greater percentages of pragmatists and receptives who spend most of their time in daily, clinical practice are faced with challenging productivity standards that make KT of EBCPGs and OMs difficult (APTA, 2015a).

\section{Strengths and Limitations}

The strengths of the study included the overall response rate of $57 \%$ to the survey and the descriptive study design. Most literature would support that a $25 \%$ response to email surveys is regarded as a good response, and this research represents a much more significant response rate (Creswell, 2002; Fowler, 2008; Portney \& Watkins, 2008). The descriptive design allowed for a rich data set and detailed analysis of the course participants in a natural and unchanged environment. The descriptive design of the study is a precursor to future, more focused quantitative designs that could be quasiexperimental and experimental in nature. Also, use of the standardized survey tools and the data analysis combining the two survey tools can be considered a significant strength of this study. Although prior studies determined the prevalence of practice style traits in other samples, this study was the first to determine practice style traits of physical therapists in the United States. These subjects had self-selected to attend a continuing education course specific to the use of OMs, and the findings of the practice style traits were then combined with the responses from the EBP Questionnaire.

Prior research on EBP for the assessment of beliefs, attitudes, knowledge, and behavior, however, the reliability was found to be rather low in many survey items and the validity was not clearly described in the publication (Bernhardsson \& Larsson, 2013; D. U. Jette et al., 2003). The only other published research that attempted to capture a 
physical therapist's attitudes, barriers, and prerequisites for application of OMs was carried out using a nonstandardized and invalidated survey tool (D. U. Jette et al., 2009). The EBP Questionnaire was only formally validated to measure self-reported attitudes, knowledge, behavior, barriers and prerequisites related to EBP and EBCPGs with physical therapists practicing in primary care in Sweden. Use of this tool independently and in combination with the Practice Style Questionnaire have not been published elsewhere in the literature. It should be noted that the EBP Questionnaire, as a standardized and validated survey tool, was used in its entirety, with only one modification. This modification included the term OMs alongside EBCPGs each time EBCPGs was used. Outcome measures are one example of the use of evidence in EBP and are a significant component of EBCPGs, which are currently in development.

Although the descriptive nature of the study is a strength, it is also considered a weakness because the results of the study do not provide definitive answers to the hypotheses posed, only recommendations. In addition, the study design was survey in nature; therefore, with any survey research there is a potential for social desirability bias, as the physical therapists may be more likely to indicate answers to both survey tools that favor EBP behaviors. However, the high prevalence of pragmatists may suggest otherwise. An additional limitation of this study was the unexpected conclusion of the evidence-based continuing education course specific to the use of OMs. The initial study design was a quasi-experimental, pre- and postcourse survey using the same survey tools; however this research plan needed to be amended as future course offerings were canceled. 


\section{Implications of Research}

The implications of this research are far reaching beyond the profession of physical therapy. Knowing the practice style traits for continuing education course participants prior to the start of the educational intervention may lead course facilitators to modify the course delivery method so that curriculum is tailored to the learner. Educational interventions, supported by social cognitive and educational theories, need to be multifaceted and target specific populations for optimal effectiveness (Grimshaw et al., 2002; Grimshaw et al., 2012). Examples could include the use of small group discussion, active-learning strategies with the use of patient cases for direct application, and scenariobased role-playing activities to foster clinical decision-making and KT. In addition, knowledge of participants' practice style trait may be factored in to create in-class activities and small group discussions highlighting the benefits of each trait. For example, if course participants were who were seekers were all grouped together during an activity, one would expect that they would be very eager to search and locate the evidence; however, they would be the least efficient group to actually translate the knowledge into clinical practice. An interdisciplinary healthcare team made up of individuals representing all four practice style traits would be highly efficient in searching and applying the evidence. It is not to say that one practice style trait is superior to the others, but it is the acknowledgment of one's trait and self-efficacy that fosters optimal inter-group collaboration and dynamics for $\mathrm{KT}$ into daily clinical practice. In addition, continuing education courses can model this type of group activity so that when clinicians return to their place of work, the variety of traits can ignite other members of their interdisciplinary teams to model the same type of group format to optimize KT. Also, 
knowledge of one's own and those of team members' practice style trait can enhance collaboration with activities such as journal club, brokering of knowledge, self-directed work teams, mentor-mentee relationships, and chart audits; all of which are activities that foster KT.

Specific to this study, the profession of physical therapy can acknowledge the significant percentage of seekers, as compared to the prior published research, who attended their regional coursework on OMs. The profession of physical therapy can use this information in two ways. The first is to consider course offerings appealing to a higher percentage of seekers, and the second is to consider alternative delivery methods that would appeal more to traditionalists and receptives, thereby attempting to capture other practice style traits. Alternate course delivery methods could be increasing the number of webinars and offering ongoing support after the formal course has ended to enhance the use and continued application of knowledge. In addition, specialty sections of healthcare organizations can positively acknowledge their course attendees as also being a large percentage of their own section members. Specialty sections' members represented a high percentage of seekers who can continue to foster KT with respect to EBCPGs and OMs in their daily, clinical environment.

As the importance of OMs continues to drive the use of evidence in EBP, this study's results can be used to implement the next level of KT in clinical practice. Evidence-based clinical practice guidelines represent this next level, and the APTA has organized numerous groups of researchers and reviewers to begin implementation in 2015. Because OMs and EBCPGs are tools to assist in bridging the gap between research and clinical practice, it is important to understand the variables of KT and its supporting 
theories. As a profession, we cannot truly move forward with this implementation until we are more knowledgeable about capturing physical therapists' practice style traits from a larger sample. In an ideal teaching and learning environment, a physical therapist's practice style trait could be tagged or cued to then connect to certain delivery methods for content related to OMs and EBCPGs, which would ultimately enhance KT and patient outcomes.

Use of the EBP Questionnaire in the United States was the first use of a standardized tool to identify variables that underlie the behaviors of the physical therapist. Knowledge about the behaviors and attitudes of the physical therapist yields information about the factors that influence the application of OMs and EBCPGs. For example, knowing that the greatest percentage of practice style traits is represented by the pragmatists, it would be imperative to first provide guidelines in an efficient manner and then devise a system to track their use, such as the use of a free app connected to personal devices and connection with the electronic medical record. Delivery methods which are multifaceted, for example in the form of electronic algorithms, could be used and tracked over time. Alignment of the best evidence and established databases for OMs and EBCPGs need to capture usability of the current and future resources and continually track use and progress over time. Future research could also consider studying KT of EBCPGs from both a payer and patient perspective.

\section{Conclusion}

The majority of past course participants of the evidence-based continuing education course specific to the use of OMs were defined as pragmatists and hence are varied in both how they weigh evidence versus experience and their degree of conformity 
with evidence in clinical practice. Pragmatists are, however, very practical in terms of engaging with and using evidence in their clinical environment (Green et al., 2002; Green et al., 2007). It is also interesting to note that this study did not identify any traditionalists in the subject pool, and the percentage of seekers (28\%) was much greater than prior published research. The differences in practice style traits show that physical therapists differ in their attitudes toward new information and how evidence is applied clinically. These differences can be measured and are quantifiable (Green et al., 2002). When practice style traits were compared to the results of the four domains of the EBP Questionnaire, only the questions in the behavior domain were found to be significant between groups. It is interesting to note that $69 \%$ of participants in this study reported using EBCPGs and OMs in their daily clinical environment compared to the $48 \%$ published in prior research (D. U. Jette et al., 2009). This increase in KT could be attributed to the subjects in this study having attended an evidence-based continuing education course specific to the use and application of OMs. Also, this difference can support the fruitful efforts of KT and educational interventions that have emerged over the past 6 years.

Future research should be aimed at using the practice style traits to enhance the creation and application of knowledge in the KTA cycle by offering multifaceted and technology savvy interventions. There is a significant opportunity for future research to further engage members of the physical therapy profession with continuing education interventions, as such a high percentage reported that they wanted more knowledge. Also, future research should continue to develop additional evidence for interventions with an emphasis on how this evidence will also be translated into clinical practice. 
Additionally, a closer look and future research should investigate the profession's large percentage of pragmatists and their barriers to KT of EBCPGs and OMs within the local environment and consideration within the context of the larger healthcare organization. Methodologies of future studies should include the use of action phases in the KTA cycle, as supported by the cognitive psychology and educational theories. 


\section{References}

Aarons, G. A., Ehrhart, M. G., Farahnak, L. R., \& Sklar, M. (2014). Aligning leadership across systems and organizations to develop a strategic climate for evidencebased practice implementation. Annual Review of Public Health, 35(1), 255-274. doi:10.1146/annurev-publhealth-032013-182447

Ajzen, I. (1991). The theory of planned behavior. Organizational Behavior and Human Decision Processes, 50(2), 179-211.

Ajzen, I. (2005). Attitudes, personality, and behavior. New York, NY: McGraw-Hill International.

American Physical Therapy Association (APTA). (2013). Vision 2020. Retrieved from http://www.apta.org/Vision2020/

American Physical Therapy Association (APTA). (2014a). Guide to physical therapist practice (3rd ed.). Alexandria, VA: Author.

American Physical Therapy Association (APTA). (2014b). Vision statement for the physical therapy profession and guiding principles to achieve the vision. Retrieved from http://www.apta.org/Vision/

American Physical Therapy Association (APTA). (2015a). APTA, AOTA, ASHA combine voices to speak out for providers' clinical judgment. Retrieved from http://www.apta.org/PTinMotion/News/2014/10/14/ConsensusStatementClinical Judgment/

American Physical Therapy Association (APTA). (2015b). Beyond vision 2020. Retrieved from http://www.apta.org/BeyondVision2020/

American Physical Therapy Association (APTA). (2015c). What is WCPT? Retrieved from http://www.wcpt.org/what-is

American Physical Therapy Association (APTA), Neurology Section. (2015a). Neurology section outcome measures recommendations. Retrieved from http://www.neuropt.org/professional-resources/neurology-section-outcomemeasures-recommendations

American Physical Therapy Association (APTA), Neurology Section. (2015b). Neurology section strategic plan. Retrieved from http://neuropt.org/about-us/strategic-plan2012-2016 
American Physical Therapy Association (APTA), Orthopedic Section. (2015). Welcome to the orthopedic section, APTA! Retrieved from http://www.orthopt.org/content/ home

American Physical Therapy Association (APTA), Research Section. (2015). About us. Retrieved from http://www.ptresearch.org/article/2/about-us

Baker, R., Camosso-Stefinovic, J., Gillies, C., Shaw, E. J., Cheater, F., Flottorp, S., \& Robertson, N. (2010). Tailored interventions to overcome identified barriers to change: Effects on professional practice and health care outcomes. Cochrane Database of Systematic Reviews, 2010(3). doi:10.1002/14651858.CD005470. pub2

Bandura, A. (1977). Self-efficacy: Toward a unifying theory of behavioral change. Psychological Review, 84(2), 191-215.

Bandura, A. (1982). Self-efficacy mechanism in human agency. American Psychologist, $37(2), 122-147$.

Bayley, M. T., Hurdowar, A., Richards, C. L., Korner-Bitensky, N., Wood-Dauphinee, S., Eng, J. J., . . . Harrison, M. (2012). Barriers to implementation of stroke rehabilitation evidence: Findings from a multi-site pilot project. Disability and Rehabilitation, 34(19), 1633-1638.

Beninato, M., \& Portney, L. G. (2011). Applying concepts of responsiveness to patient management in neurologic physical therapy. Journal of Neurologic Physical Therapy, 35(2), 75-81. doi:10.1097/NPT.0b013e318219308c

Benner, P. (1984). From novice to expert: Excellence and power in clinical nursing practice. Menlo Park, CA: Addison-Wesley.

Bennett, S., Tooth, L., McKenna, K., Rodger, S., Strong, J., Ziviani, J., . . . Gibson, L. (2003). Perceptions of evidence-based practice: A survey of Australian occupational therapists. Australian Occupational Therapy Journal, 50(1), 13-22.

Bernhardsson, S., \& Larsson, M. E. (2013). Measuring evidence-based practice in physical therapy: Translation, adaptation, further development, validation, and reliability test of a questionnaire. Physical Therapy, 93(6), 819-832.

Bloom, B. S. (2005). Effects of continuing medical education on improving physician clinical care and patient health: A review of systematic reviews. International Journal of Technology Assessment in Health Care, 21(03), 380-385. 
Bloom, B. S., \& Krathwohl, D. R. (1956). Taxonomy of educational objectives: The classification of educational goals. Handbook I: Cognitive domain. New York, NY: David McKay.

Bonetti, D., Johnston, M., Clarkson, J. E., Grimshaw, J., Pitts, N. B., Eccles, M., . . Glidewell, L. (2010). Applying psychological theories to evidence-based clinical practice: Identifying factors predictive of placing preventive fissure sealants. Behaviour, 16(18), 23. doi:10.1186/1748-5908-5-25

Boston University School of Public Health. (2013). Behavioral change models. Retrieved from http://sphweb.bumc.bu.edu/otlt/MPH-Modules/SB/SB721-Models/SB721Models.html

Canadian Institutes of Health Research (CIHR). (2014). More about knowledge translation at CIHR. Retrieved from http://www.cihr-irsc.gc.ca/e/39033.html

Centers for Medicare and Medicaid Services (CMS). (2015). G-codes. Retrieved from http://www.cms.gov/site-search/search-results.html?q=G\%20codes

Cochrane, A. L. (1989). Archie Cochrane in his own words: Selections arranged from his 1972 introduction to "Effectiveness and efficiency: Random reflections on the health services." Controlled Clinical Trials, 10(4), 428-433.

Cohen, S. J., Halvorson, H. W., \& Gosselink, C. A. (1994). Changing physician behavior to improve disease prevention. Preventive Medicine, 23(3), 284-291.

Collins, J. (2004). Education techniques for lifelong learning: Giving a PowerPoint presentation: The art of communicating effectively 1. Radiographics, 24(4), 1185-1192.

Commission on Accreditation in Physical Therapy Education (CAPTE). (2006). Evaluative criteria for accreditation of education programs for the preparation of physical therapists. Alexandria, VA: American Physical Therapy Association.

Conner, M., \& Norman, P. (2005). Predicting health behaviour. New York, NY: McGraw-Hill International.

Cranney, M., Warren, E., Barton, S., Gardner, K., \& Walley, T. (2001). Why do GPs not implement evidence-based guidelines? A descriptive study. Family Practice, 18(4), 359-363.

Creswell, J. W. (2002). Educational research: Planning, conducting, and evaluating quantitative and qualitative research. Upper Saddle River, NJ: Prentice Hall. 
Dawes, M., Summerskill, W., Glasziou, P., Cartabellotta, A., Martin, J., Hopayian, K., ... Osborne, J. (2005). Sicily statement on evidence-based practice. BMC Medical Education, 5(1), 1. doi:10.1186/1472-6920-5-1

Deyo, R. A., \& Carter, W. B. (1992). Strategies for improving and expanding the Application of health status measures in clinical settings: A researcher-developer viewpoint. Medical Care, 30(5), 176-186.

Deyo, R. A., \& Patrick, D. L. (1989). Barriers to the use of health status measures in clinical investigation, patient care, and policy research. Medical Care, 27(Suppl.), S254-S268.

Duke University Medical Center. (2015). What is evidence-based practice (EBP)? Retrieved from http://guides.mclibrary.duke.edu/c.php?g=158201\&p=1036021

Dumoulin, C., Korner-Bitensky, N., \& Tannenbaum, C. (2007). The cross Canada study of stroke rehabilitation: Finding on the identification, assessment and management of urinary incontinence after stroke. Stroke, 38(10), 2745-2751.

Duncan, P. W., Horner, R. D., Reker, D. M., Samsa, G. P., Hoenig, H., Hamilton, B., .. . Dudley, T. K. (2002). Adherence to postacute rehabilitation guidelines is associated with functional recovery in stroke. Stroke, 33(1), 167-178.

Eccles, M. P., Grimshaw, J. M., Johnston, M., Steen, N., Pitts, N. B., Thomas, R., . . Walker, A. (2007). Applying psychological theories to evidence-based clinical practice: Identifying factors predictive of managing upper respiratory tract infections without antibiotics. Implementation Science, 2(1), 26.

Ely, J. W., Osheroff, J. A., Ebell, M. H., Chambliss, M. L., Vinson, D. C., Stevermer, J. J., \& Pifer, E. A. (2002). Obstacles to answering doctors' questions about patient care with evidence: Qualitative study. British Medical Journal, 324(7339), 710.

Estabrooks, C. A., Thompson, D. S., Lovely, J. J. E., \& Hofmeyer, A. (2006). A guide to knowledge translation theory. Journal of Continuing Education in the Health Professions, 26(1), 25-36.

Field, M. J., \& Lohr, K. N. (Eds.). (1992). Guidelines for clinical practice: From development to use. Institute of Medicine. Washington, DC: National Academy Press.

Flores, G., Lee, M., Bauchner, H., \& Kastner, B. (2000). Pediatricians' attitudes, beliefs, and practices regarding clinical practice guidelines: A national survey. Pediatrics, 105(3), 496-501. 
Forsetlund, L., Bjørndal, A., Rashidian, A., Jamtvedt, G., O’Brien, M. A., Wolf, F., ... Oxman, A. D. (2009). Continuing education meetings and workshops: Effects on professional practice and health care outcomes. Cochrane Database of Systematic Reviews, 2009(2).

Fowler, F. J., Jr. (2008). Survey research methods. Thousand Oaks, CA: Sage.

Fox, R. D., \& Bennett, N. L. (1998). Learning and change: Implications for continuing medical education. British Medical Journal, 316(7129), 466-468.

Freeman, A. C., \& Sweeney, K. (2001). Why general practitioners do not implement evidence: Qualitative study. British Medical Journal, 323(7321), 1100-1102.

Fritz, J. M., Cleland, J. A., \& Brennan, G. P. (2007). Does adherence to the guideline recommendation for active treatments improve the quality of care for patients with acute low back pain delivered by physical therapists? Medical Care, 45(10), 973-980.

Fulk, G., \& Field-Fote, E. C. (2011). Measures of evidence in evidence-based practice [Editorial introduction]. Journal of Neurologic Physical Therapy, 35(2), 55-56. doi:10.1097/NPT.0b013e31821ba134

Garland, A. F., Kruse, M., \& Aarons, G. A. (2003). Clinicians and outcome measurement: What's the use? Journal of Behavioral Health Services \& Research, 30(4), 393-405.

Gilbody, S., Whitty, P., Grimshaw, J., \& Thomas, R. (2003). Educational and organizational interventions to improve the management of depression in primary care: A systematic review. Journal of the American Medical Association, 289(23), 3145-3151.

Godin, G., Bélanger-Gravel, A., Eccles, M., \& Grimshaw, J. (2008). Healthcare professionals' intentions and behaviours: A systematic review of studies based on social cognitive theories. Implementation Science, 3(36), 1-12.

Goldstein, M. S., Elliott, S. D., \& Guccione, A. A. (2000). The development of an instrument to measure satisfaction with physical therapy. Physical Therapy, 80(9), 853-863.

Goldstein, M. S., Scalzitti, D. A., Craik, R. L., Dunn, S. L., Irion, J. M., Irrgang, J., . . . \& Shields, R. K. (2011). The revised research agenda for physical therapy. Physical Therapy, 91(2), 165-174. 
Graham, I. D., Logan, J., Harrison, M. B., Straus, S. E., Tetroe, J., Caswell, W., \& Robinson, N. (2006). Lost in knowledge translation: Time for a map? Journal of Continuing Education in the Health Professions, 26(1), 13-24.

Green, L. A., Gorenflo, D. W., \& Wyszewianski, L. (2002). Validating an instrument for selecting interventions to change physician practice patterns. Journal of Family Practice, 51(11), 938-942.

Green, L. A., Wyszewianski, L., Lowery, J. C., Kowalski, C. P., \& Krein, S. L. (2007). An observational study of the effectiveness of practice guideline implementation strategies examined according to physicians' cognitive styles. Implementation Science, 2(1), 41. doi:10.1186/1748-5908-2-41

Grimshaw, J. M., Eccles, M. P., Lavis, J. N., Hill, S. J., \& Squires, J. E. (2012). Knowledge translation of research findings. Implementation Science, 7(50), 21-36.

Grimshaw, J. M., Eccles, M. P., Walker, A. E., \& Thomas, R. E. (2002). Changing physicians' behavior: What works and thoughts on getting more things to work. Journal of Continuing Education in the Health Professions, 22(4), 237-243.

Grimshaw, J. M., Shirran, L., Thomas, R., Mowatt, G., Fraser, C., Bero, L., . . O’Brien, M. A. (2001). Changing provider behavior: An overview of systematic reviews of interventions. Medical Care, 39(8), 2-45.

Grol, R. P., Bosch, M. C., Hulscher, M. E., Eccles, M. P., \& Wensing, M. (2007). Planning and studying improvement in patient care: The use of theoretical perspectives. Milbank Quarterly, 85(1), 93-138.

Grol, R. P., Wensing, M., Bosch, M., Hulscher, M., \& Eccles, M. (2013). Theories on implementation of change in healthcare. In R. Grol, M. Wensing, M. Eccles, \& D. Davis (Eds.), Improving patient care: The implementation of change in health care (2nd ed., pp. 18-39). Hoboken, NJ: Wiley-Blackwell.

Hadouda, S., Laroui, H. R., Lemay, A., Martin, B., Korner-Bitensky, N., Menon, A., . . . Ahmed, S. (2009). Practice style traits of student occupational therapists and physical therapists. Canadian Journal of Occupational Therapy, 76(2), 98-106.

Haigh, R., Tennant, A., Biering-Sorensen, F., Grimby, G., Marincek, C., Phillips, S., . . . Thonnard, J.-L. (2001). The use of outcome measures in physical medicine and rehabilitation within Europe. Journal of Rehabilitation Medicine, 33(6), 273-278.

Harris, S. R. (1996). How should treatments be critiqued for scientific merit? Physical Therapy, 76(2), 175-181. 
Haynes, B., \& Haines, A. (1998). Barriers and bridges to evidence based clinical practice. British Medical Journal, 317(7153), 273-276.

Herbert, R., Jamtvedt, G., Mead, J., \& Hagen, K. B. (2005). Outcome measures measure outcomes, not effects of intervention. Australian Journal of Physiotherapy, 51(1), $3-4$.

Hrisos, S., Eccles, M., Johnston, M., Francis, J., Kaner, E. F., Steen, N., \& Grimshaw, J. (2008a). An intervention modelling experiment to change GPs' intentions to implement evidence-based practice: Using theory-based interventions to promote GP management of upper respiratory tract infection without prescribing antibiotics \#2. BMC Health Services Research, 8(1), 10. doi:10.1186/14726963-8-10

Hrisos, S., Eccles, M., Johnston, M., Francis, J., Kaner, E. F., Steen, N., \& Grimshaw, J. (2008b). Developing the content of two behavioural interventions: Using theorybased interventions to promote GP management of upper respiratory tract infection without prescribing antibiotics \#1. BMC Health Services Research, 8(1), 11. doi:10.1186/1472-6963-8-11

Huijbregts, M. P., Myers, A. M., Kay, T. M., \& Gavin, T. S. (2002). Systematic outcome measurement in clinical practice: Challenges experienced by physiotherapists. Physiotherapy Canada, 54(1), 25-31.

International Classification of Functioning, Disability, and Health (ICF). (2001). Classifications. Retrieved from http://www.who.int/classifications/icf/en/

Jensen, G. M. (2011). Learning: What matters most. Physical Therapy, 91(11), 1674-1689.

Jette, A. M., \& Haley, S. M. (2005). Contemporary measurement techniques for rehabilitation outcomes assessment. Journal of Rehabilitation Medicine, 37(6), 339-345.

Jette, D. U., Bacon, K., Batty, C., Carlson, M., Ferland, A., Hemingway, R. D., . . Volk, D. (2003). Evidence-based practice: Beliefs, attitudes, knowledge, and behaviors of physical therapists. Physical Therapy, 83(9), 786-805.

Jette, D. U., Halbert, J., Iverson, C., Miceli, E., \& Shah, P. (2009). Use of standardized outcome measures in physical therapist practice: Perceptions and applications. Physical Therapy, 89(2), 125-135.

Kajermo, K. N., Nordström, G., Krusebrant, Å., \& Björvell, H. (1998). Barriers to and facilitators of research utilization, as perceived by a group of registered nurses in Sweden. Journal of Advanced Nursing, 27(4), 798-807. 
Kay, T. M., Myers, A. M., \& Huijbregts, M. P. (2001). How far have we come since 1992? A comparative survey of physiotherapists' use of outcome measures. Physiotherapy Canada, 53(4), 268-275.

Knowles, M. S. (1970). The modern practice of adult education (Vol. 41). New York, NY: Association Press New York.

Knowles, M. S. (1980). The modern practice of adult education: From pedagogy to andragogy (Rev ed.). Englewood Cliffs, NJ: Prentice-Hall.

Korner-Bitensky, N., Desrosiers, J., \& Rochette, A. (2008). A national survey of occupational therapists' practices related to participation post-stroke. Journal of Rehabilitation Medicine, 40(4), 291-297.

Korner-Bitensky, N., Menon-Nair, A., Thomas, A., Boutin, E., \& Arafah, A. M. (2008). Practice style traits: Do they help explain practice behaviours of stroke rehabilitation professionals? Journal of Rehabilitation Medicine, 39(9), 685-692.

Kramer, A., \& Holthaus, D. (2006). Uniform patient assessment for post-acute care: Final report. Aurora, CO: US Division of Health Care Policy and Research.

Krathwohl, D. R. (2002). A revision of Bloom's taxonomy: An overview. Theory Into Practice, 41(4), 212-218.

Laidley, T. L., \& Braddock, C. H., III. (2000). Role of adult learning theory in evaluating and designing strategies for teaching residents in ambulatory settings. Advances in Health Sciences Education, 5(1), 43-54.

Lansky, D., Butler, J., \& Waller, F. T. (1992). Using health status measures in the hospital setting: From acute care to 'outcomes management.' Medical Care, 30(Suppl.), S57-S73.

Lewin, B. J. (1998). Perceived barriers to research utilization: A survey of four therapies. International Journal of Therapy and Rehabilitation, 5(3), 151-155.

Lewis, A., \& Bolden, K. (1989). General practitioners and their learning styles. Journal of the Royal College of General Practitioners, 39(322), 187-189.

Liddle, S. D., David Baxter, G., \& Gracey, J. H. (2009). Physiotherapists' use of advice and exercise for the management of chronic low back pain: A national survey. Manual Therapy, 14(2), 189-196.

MacDermid, J. C., \& Graham, I. D. (2009). Knowledge translation: Putting the "practice" in evidence-based practice. Hand Clinics, 25(1), 125-143. 
Maher, C. G., Moseley, A. M., Sherrington, C., Elkins, M. R., \& Herbert, R. D. (2008). A description of the trials, reviews, and practice guidelines indexed in the PEDro database. Physical Therapy, 88(9), 1068-1077. doi:10.2522/ptj.20080002

Mazmanian, P. E., \& Davis, D. A. (2002). Continuing medical education and the physician as a learner: Guide to the evidence. Journal of the American Medical Association, 288(9), 1057-1060.

McCluskey, A. (2003). Occupational therapists report a low level of knowledge, skill and involvement in evidence-based practice. Australian Occupational Therapy Journal, 50(1), 3-12.

MELLBandura. (2015). Bandura and self efficacy. Retrieved from http://mellbandura. wikispaces.com/Bandura+and+Self+Efficacy.

Menon, A., Korner-Bitensky, N., Kastner, M., McKibbon, K., \& Straus, S. (2009). Strategies for rehabilitation professionals to move evidence-based knowledge into practice: A systematic review. Journal of Rehabilitation Medicine, 41(13), 1024-1032.

Menon-Nair, A., Korner-Bitensky, N., \& Ogourtsova, T. (2007). Occupational therapists' identification, assessment, and treatment of unilateral spatial neglect during stroke rehabilitation in Canada. Stroke, 38(9), 2556-2562.

Merriam, S. B., Caffarella, R. S., \& Baumgartner, L. M. (2012). Learning in adulthood: A comprehensive guide. San Francisco, CA: Wiley.

Metcalfe, C., Lewin, R., Wisher, S., Perry, S., Bannigan, K., \& Moffett, J. K. (2001). Barriers to implementing the evidence base in four NHS therapies: Dietitians, occupational therapists, physiotherapists, speech and language therapists. Physiotherapy, 87(8), 433-441.

Nelson, E. C., \& Berwick, D. M. (1989). The measurement of health status in clinical practice. Medical Care, 27(Supp1.), S77-S90.

Neurologic Section of the American Physical Therapy Association. (2015). Neurology section strategic plan. Retrieved from http://www.neuropt.org/about-us/strategicplan-2012-2016

O’Brien, M. A., Rogers, S., Jamtvedt, G., Oxman, A. D., Odgaard-Jensen, J., Kristoffersen, D. T., . . Davis, D. (2007). Educational outreach visits: Effects on professional practice and health care outcomes. Cochrane Database of Systematic Reviews, 4(4), 1-64. doi:10.1002/14651858 
O’Sullivan, S. B., Schmitz, T. J., \& Fulk, G. (2014). Physical rehabilitation (6th ed.). Philadelphia, PA: F. A. Davis.

Overmeer, T., Linton, S. J., Holmquist, L., Eriksson, M., \& Engfeldt, P. (2005). Do evidence-based guidelines have an impact in primary care? A cross-sectional study of Swedish physicians and physiotherapists. Spine, 30(1), 146-151.

Perkins, M., Jensen, P., Jaccard, J., Gollwitzer, P., Oettingen, G., Pappadopulos, E., \& Hoagwood, K. (2007). Applying theory-driven approaches to understanding and modifying clinicians' behavior: What do we know? Psychiatric Services, 58(3), 342-348.

Pollock, A. S., Legg, L., Langhorne, P., \& Sellars, C. (2000). Barriers to achieving evidence-based stroke rehabilitation. Clinical Rehabilitation, 14(6), 611-617.

Portney, L., \& Watkins, M. (2008). Foundations of clinical research: Applications to practice. Upper Saddle River, NJ: Prentice Hall.

Potter, K., Fulk, G. D., Salem, Y., \& Sullivan, J. (2011). Outcome measures in neurological physical therapy practice: Part I. Making sound decisions. Journal of Neurologic Physical Therapy, 35(2), 57-64. doi:10.1097/NPT.1090b1013e 318219a318251a

Prochaska, J. O., \& Velicer, W. F. (1997). The transtheoretical model of health behavior change. American Journal of Health Promotion, 12(1), 38-48.

Ramsay, C. R., Thomas, R. E., Croal, B. L., Grimshaw, J. M., \& Eccles, M. P. (2010). Using the theory of planned behaviour as a process evaluation tool in randomised trials of knowledge translation strategies: A case study from UK primary care. Implementation Science, 5(1), 71. doi:10.1186/1748-5908-5-71

Rehabilitation Measures Database. (2015). Instruments. Retrieved from http://www.rehabmeasures.org/default.aspx

Rochette, A., Korner-Bitensky, N., \& Desrosiers, J. (2007). Actual vs best practice for families post-stroke according to three rehabilitation disciplines. Journal of Rehabilitation Medicine, 39(7), 513-519.

Rothstein, J. M. (2001). Autonomous practice or autonomous ignorance? Physical Therapy, 81(10), 1620-1621.

Rothstein, J. M., Echternach, J. L., \& Riddle, D. L. (2003). The Hypothesis-Oriented Algorithm for Clinicians II (HOAC: II): A guide for patient management. Physical Therapy, 83(5), 455-470. 
Rutten, G. M., Degen, S., Hendriks, E. J., Braspenning, J. C., Harting, J., \& Oostendorp, R. A. (2010). Adherence to clinical practice guidelines for low back pain in physical therapy: Do patients benefit? Physical Therapy, 90(8), 1111-1122.

Rycroft-Malone, J., \& Bucknall, T. (2013). Models and frameworks for implementing evidence-based practice: Linking evidence to action. Chichester, England: Wiley.

Sackett, D. L. (1997). Evidence-based medicine. Seminars in Perinatology, 21(1), 3-5.

Sackett, D. L., \& Haynes, R. (2002). The architecture of diagnostic research. British Medical Journal, 324(7336), 539-541.

Sackett, D. L., Rosenberg, W., Gray, J., Haynes, R. B., \& Richardson, W. S. (1996). Evidence-based medicine: What it is and what it isn't. British Medical Journal, 312(7023), 71-72.

Salbach, N. M., Jaglal, S. B., Korner-Bitensky, N., Rappolt, S., \& Davis, D. (2007). Practitioner and organizational barriers to evidence-based practice of physical therapists for people with stroke. Physical Therapy, 87(10), 1284-1303.

Scalzitti, D. A. (2001). Evidence-based guidelines: Application to clinical practice. Physical Therapy, 81(10), 1622-1628.

Schenkman, M., Deutsch, J. E., \& Gill-Body, K. M. (2006). An integrated framework for decision making in neurologic physical therapist practice. Physical Therapy, 86(12), 1681-1702.

Stevenson, T. J. (2001). Detecting change in patients with stroke using the Berg Balance Scale. Australian Journal of Physiotherapy, 47(1), 29-38.

Straus, S., Tetroe, J., \& Graham, I. D. (2013). Knowledge translation in health care: Moving from evidence to practice. Oxford, England: Wiley-Blackwell.

Stuart, G. W., Tondora, J., \& Hoge, M. A. (2004). Evidence-based teaching practice: Implications for behavioral health. Administration and Policy in Mental Health and Mental Health Services Research, 32(2), 107-130.

Sullivan, J. E., Andrews, A. W., Lanzino, D., Peron, A., \& Potter, K. A. (2011). Outcome measures in neurological physical therapy practice: Part II. A patient-centered process. Journal of Neurologic Physical Therapy, 35(2), 65-74.

doi:10.1097/NPT.1090b1013e31821a31824eb

Tabak, R. G., Khoong, E. C., Chambers, D. A., \& Brownson, R. C. (2012). Bridging research and practice: Models for dissemination and implementation research. American Journal of Preventive Medicine, 43(3), 337-350. 
Tilson, J. K., Kaplan, S. L., Harris, J. L., Hutchinson, A., Ilic, D., Niederman, R., . . . Zwolsman, S. E. (2011). Sicily statement on classification and development of evidence-based practice learning assessment tools. BMC Medical Education, 11(1), 78. doi:10.1186/1472-6920

University of Southern California (USC) Libraries. (2015). Research guides. Retrieved from http://libguides.usc.edu/c.php?g=235034\&p=1559832

Value Based Management.net. (2014). Summary of the TPB by Adzen-Abstract. Retrieved from http://www.valuebasedmanagement.net/methods_ajzen_theory_ planned_behaviour.html

Van Peppen, R. P., Maissan, F. J., Van Genderen, F. R., Van Dolder, R., \& Van Meeteren, N. L. (2008). Outcome measures in physiotherapy management of patients with stroke: A survey into self-reported use, and barriers to and facilitators for use. Physiotherapy Research International, 13(4), 255-270.

Weinstein, N. D., Lyon, J. E., Sandman, P. M., \& Cuite, C. L. (1998). Experimental evidence for stages of health behavior change: The precaution adoption process model applied to home radon testing. Health Psychology, 17(5), 445-453.

Wensing, M., Bosch, M., Foy, R., Van der Weijden, T., Eccles, M., \& Grol, R. (2005). Factors in theories on behaviour change to guide implementation and quality improvement in healthcare. Nijmegen, Centre for Quality of Care Research (WOK), 10(4), 203-211.

Woolf, S. H. (2008). The meaning of translational research and why it matters. Journal of American Medical Association, 299(2), 211-213.

World Health Organization (WHO). (2002). Towards a common language for functioning, disability and health: ICF. Geneva, Switzerland: Author. 
Appendix A

Practice Style Questionnaire

We are interested in your views about evidence-based practice. Please rate your agreement or disagreement with each statement on the following scale:

$\mathrm{SA}=$ Strongly Agree; $\mathrm{A}=$ Agree; $\mathrm{N}=$ Neutral; $\mathrm{D}=$ Disagree; $\mathrm{SD}=$ Strongly Disagree

1. Clinical experience is more important than randomized controlled trials

SA A N D SD

2. I am comfortable practicing in way different than other physical therapists

SA A N D SD

3. Evidence-based practice makes a lot of sense to me

SA A N D SD

4. I don't have the time to read up on every practice decision

SA A N D SD

5. It is best to change the way I treat a certain problem when my local colleagues are making the same changes

SA A N D SD

6. I follow practice guidelines if they are not too much hassle

SA A N D SD

7. The opinions of respected authorities should guide clinical practice

SA A N D SD

8. I am too busy taking care of patients to keep up with the recent literature

SA A N D SD

9. Clinical experience is the most reliable way to know what really works

SA A N D SD

10. I am uncomfortable doing things differently from the way I was trained

SA A N D SD

11. I am often critical of accepted practices

SA A N D SD

12. Patient care should be based where possible on randomized controlled trials, rather than the opinions of respected authorities

SA A N D SD

13. My colleagues consider me to be someone who marches to my own drummer

SA A N D SD

14. I follow practice guidelines as long as they don't interfere too much with the flow of patients

SA A N D SD 
15. It is not prudent to practice out of step with other physical therapists in my area

SA A N D SD

16. The best practice guidelines are based on the results of randomized controlled trials

SA A N D SD

17. Evidence-based practice is not very practical in real patient care

SA A N D SD 
Appendix B

\section{Evidence-Based Practice Questionnaire}

Questionnaire on the Use of and Attitudes Toward Evidence-Based Practice (EBP) and Guidelines in Physical Therapy

Evidence-based practice is defined as integrating the best available external clinical evidence from systematic research with individual clinical experience and patient preferences (Sackett, Rosenberg, Gray, Haynes, \& Richardson, 1996).

A. The first part of the questionnaire is about personal/demographic information.

1. Are you male or female?

Male Female

2. To which age group do you belong?

$$
\text { 20-29 years 30-39 years 40-49 years 50-59 years } 60+\text { years }
$$

3. How many years have you worked as a physical therapist?

$$
<3 \text { years 3-5 years 6-10 years 11-15 years 16-20 years }>20 \text { years }
$$

4. What is you highest degree earned?

Bachelor's Degree

Master's Degree

Clinical Doctorate/DPT

Transitional Doctorate/t-DPT

Terminal Doctorate-PhD, EdD, DHSc, DHS

5. Are you an APTA member?

$$
\text { Yes No }
$$

5a. Are you an APTA section member?

$$
\text { Yes No }
$$

If yes, which section(s); please specify:

5b. Do you currently hold an American Board of Physical Therapy Specialties certification?

$$
\text { Yes No }
$$

If yes, which certification(s); please specify: 
6. In which practice setting do you work?

Acute care

Home Health

Inpatient rehabilitation

Outpatient rehabilitation

Skilled Nursing

Long-term Care

Other: (please specify)

7. How many physical therapists work at your main place of work?

$$
<3 \quad 3-5 \quad 6-10 \quad 11-15 \quad>15
$$

8. What portion of your total work time do you spend with patient care (including patient administration)?

$$
<25 \% \quad 26-50 \% \quad 51-75 \% \quad>75 \%
$$

B. The following part is about attitudes toward, use of, and perceived benefits and limitations of EBP.

Evidence-based practice is defined as integrating the best available external clinical evidence from systematic research with individual clinical experience and patient preferences (Sackett et al., 1996).

Answer the questions by checking the response alternative you consider the most suitable.

9. I consider it necessary to apply EBP in the daily practice of physical therapy.

$$
\text { Strongly Disagree Disagree Neutral Agree Strongly Agree }
$$

10. I think it creates unreasonable demands to apply EBP in my daily work.

Strongly Disagree Disagree Neutral Agree Strongly Agree

11. I want to learn and improve the knowledge and skills necessary to apply EBP in my work.

Strongly Disagree Disagree Neutral Agree Strongly Agree

12. Strong evidence is lacking for most treatments that I use for my patients.

Strongly Disagree Disagree Neutral Agree Strongly Agree 
13. EBP can help me make decisions in the choice of treatment.

Strongly Disagree Disagree Neutral Agree Strongly Agree

14. Number of scientific articles related to my clinical work that I read, during a typical month.

1 article 2-5 articles 6-10 articles 11-15 articles 16+articles

15. Number of times I use PubMed or other databases to search literature that is relevant to my clinical work, during a typical month.
1 time
2-5 times
6-10 times
11-15 times
$16+$ times

16. I know how to access relevant databases.

Strongly Disagree Disagree Neutral Agree Strongly Agree

17. At my place of work the use of current research is encouraged.

Strongly Disagree Disagree Neutral Agree Strongly Agree

18. I feel confident in my ability to find relevant research to answer my clinical questions.

Strongly Disagree Disagree Neutral Agree Strongly Agree

19. I feel confident in my ability to treat my patients according to current evidence.

Strongly Disagree Disagree Neutral Agree Strongly Agree

\section{The following part is about attitudes toward and use of clinical practice guidelines.}

According to Field and colleagues (1992), guidelines are "systematically developed recommendations with the purpose to facilitate for caregivers and patients to make decisions about suitable treatment in specific situations" (p. 2).

In this survey, guidelines means evidence-based clinical practice guidelines for physical therapy. Specific to the Neurologic Practice Essentials: A Measurement Toolbox course that you previously attended, consider the clinical practice guidelines that were offered as they relate to the knowledge and application of outcome measures.

20. I consider it important that easily available evidence-based guidelines/outcome measures related to my work exist.

$$
\text { Strongly Disagree Disagree Neutral Agree Strongly Agree }
$$

21. I consider it important to use evidence-based guidelines/outcome measures in my work.

$$
\text { Strongly Agree Disagree Neutral Agree Strongly Agree }
$$


22. I'm aware that evidence-based guidelines/outcome measures for diagnoses relevant to my work exist.

$$
\text { Yes Partially No }
$$

23. I know how and where to find evidence-based guidelines/outcome measures related to my work on the Internet.

$$
\text { Yes Partially No }
$$

24. I have fast and easy access to relevant evidence-based guidelines/outcome measures at my place of work.

$$
\text { Strongly Agree Disagree Neutral Agree Strongly Agree }
$$

25. I use evidence-based guidelines/outcome measures in my work.

Very seldom or never Seldom Sometimes Quite Often Very often

26. I can integrate the patients' preferences with evidence-based guidelines/outcome measures.

Strongly Agree Disagree Neutral Agree Strongly Agree

27. Evidence-based guidelines/outcome measures are importance to facilitate my work.

Strongly Agree Disagree Neutral Agree Strongly Agree

28. Evidence-based guidelines/outcome measures are important so that the patients receive the best possible treatment.

Strongly Agree Disagree Neutral Agree Strongly Agree

29. Evidence-based guidelines/outcome measures are importance so that patients receive equal treatment.

Strongly Agree Disagree Neutral Agree Strongly Agree

30. Mark the factors below that constitute the greatest barriers to using evidence-based guidelines/outcome measures. You can mark as many as you wish.

Lack of time

None or too few guidelines exist for my patient groups

Don't know where to find guidelines

Takes too long to read guidelines

Guidelines are too general and too unspecific

Guidelines are too much "recipe" and don't let me decide what is most appropriate

Lack of support from my colleagues at my place of work

Lack of interest

Other 
30 a. If you answered "other," please state what.

31. For which diagnoses would you benefit the most from having evidence-based guidelines/outcome measures? State up to 5 diagnoses.

32. What are the 5 most frequently used outcome measures in your clinical practice?

\section{References:}

Field, M. J., \& Lohr, K. N. (Eds.). (1992). Guidelines for clinical practice: From development to use. Institute of Medicine. Washington, DC: National Academy Press, p. 27.

Sackett, D. L., Rosenberg, W., Gray, J., Haynes, R. B., \& Richardson, W. S. (1996). Evidence-based medicine: What it is and what it isn't. British Medical Journal, 312(7023), 71-72. 